Women's Narratives about Identity, Power and Agency within a Mining Organisation in South Africa

\title{
Leigh Johnstone
}

201293612

2013

Submitted in partial fulfilment of the requirements for the degree of Master of Social Science (Industrial Psychology), in the Graduate Programme in the School of Psychology, University of KwaZulu-Natal, Durban, South Africa.

Supervisor: Anil Bhagwanjee and Shaida Bobat 


\section{Declaration}

I declare that this dissertation is my own unaided work. All citations, references and borrowed ideas have been duly acknowledged. It is being submitted for the degree of Master of Industrial Psychology in the Faculty of Humanities, Development and Social Science, University of KwaZulu-Natal, Durban, South Africa. None of the present work has been submitted previously for any degree or examination in any other University.

Signature:

Leigh Johnstone

Date: 


\section{Acknowledgements}

First, and foremost, I would like to thank my Lord and Saviour Jesus Christ, who has seen me through my entire academic career, and particularly during the process of writing up this thesis. Without Your help, I would not be where I am today.

Thanks and appreciation also goes to the following people:

- My primary supervisor, Anil Bhagwanjee. I cannot begin to describe the impact you have made in my life, as my mentor, friend and counsellor, you have raised my aspirations to achieve more than I originally imagined. Thank you for your contribution to this research, your endless enthusiasm, energy and knowledge - I don't know where you get it all from!

- My co-supervisor, Shaida Bobat. You have been a role model for me since the very first day I attended one of your lectures. Thank you for constantly keeping in contact with me, and assisting me at any time of the day or night.

- The women who not only agreed to participate in this research, but who also openly engaged with me on a deeper level. Without you, this study would not have been possible.

- My friends and family, who have supported and motivated me and allowed me to keep them up late at night discussing my research ideas.

- Last, but certainly not least, thank you Michael Ford for being by my side every day, allowing me to bombard you with all my thoughts, despite being relatively foreign to you. You have been my stability throughout this year, and always manage to fill me with joy even during challenging times. 


\begin{abstract}
The purpose of this study was to examine the complexities that constitute women's narratives within a mining organisation in South Africa. A review of the literature suggests that social constructions about gender influence the way in which individuals construct narratives and meaning in their lives, which inform their ways of being. This research draws upon two main schools of thought, that is, post-modern social constructionism and post-structuralism. Based on these world views, a qualitative analysis was selected as the most appropriate research design. This research examined the narratives of nine women in senior positions from a single mining organisation, in the form of semi-structured in depth interviews carried out in September 2011. An ethnographic research design was selected, in line with the theoretical framework of this study. A thematic analysis was conducted, and the results revealed two central themes, viz. Navigating the interceptions between occupational and multiple identities; and negotiating a space for women in mining.
\end{abstract}

The nature of identity that emerged from participant's narratives was viewed as an act of weaving together the multiple strands of the self, where participants recognise the points at which these multiple strands intercept and where they diverge. So rather than merging these strands into a unified (and essentialist) self, participants seemed to recognise the fluid, dynamic and contextual sense of self and in-so-doing, participants began to, in their narrative, construct an authentic sense of self. At each interception participants are faced with (i) contradictions and ambiguity, or (ii) congruency of the self between roles, which emerged as 'identity salience'. Interceptions were interpreted as an illustration of the micro-physics of power, as postulated by Foucault (1979). In some cases, participants internalise normative and 'masculine' prescriptions 
of the self, resulting in the reification of gendered norms and the subsequent 'disciplining' of the self to embody such norms. However, participants also exercise individual and collective agency in resisting dominant ideology, thereby driving shifts in the power dynamics of society and negotiating an authentic and egalitarian self, and space for women in mining.

Keywords: women, mining, South Africa, identity, social identity, power, agency, ethnographic research, thematic analysis, Social Constructionism 


\section{TABLE OF CONTENTS}

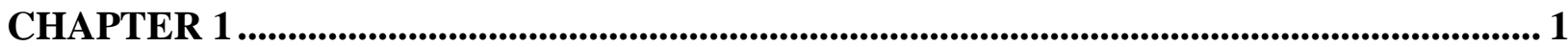

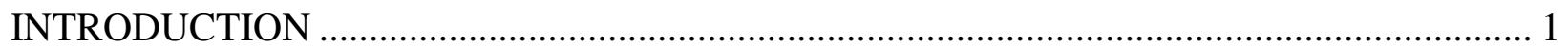

1.1 Historical Context: Women in Mining in South Africa ..................................................... 1

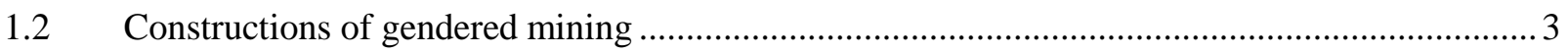

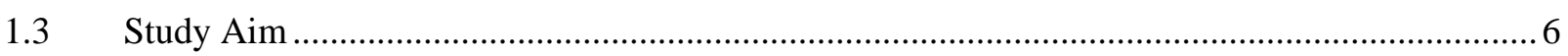

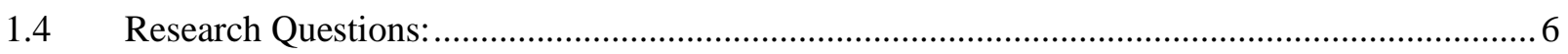

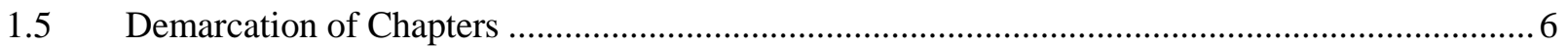

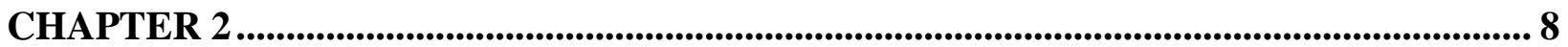

LITERATURE REVIEW AND THEORETICAL FRAMEWORK ........................................ 8

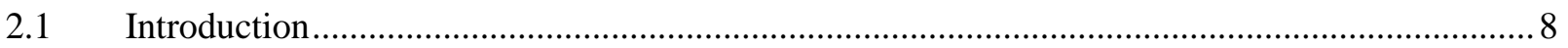

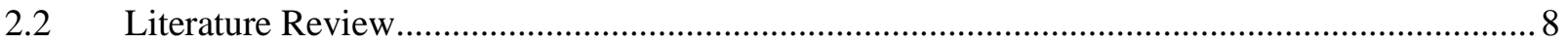

2.2.1 The historical context of labour relations in South Africa ....................................................... 8

2.2.2 The Dialectic of Women in the Workplace .............................................................................. 11

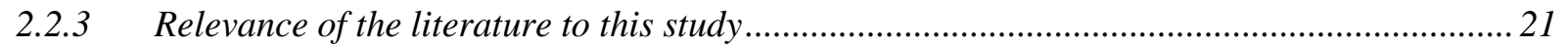

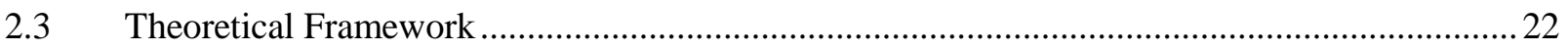

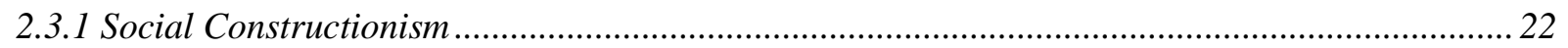

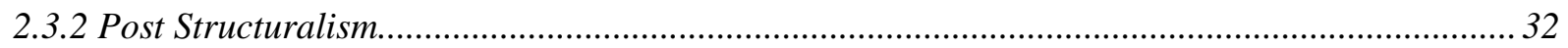

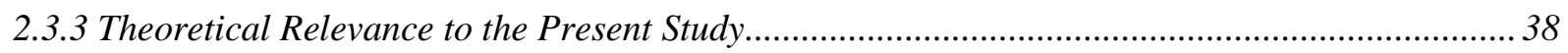

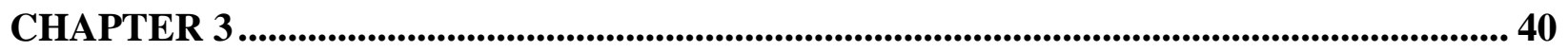

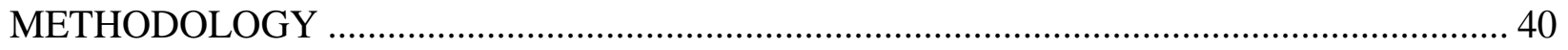

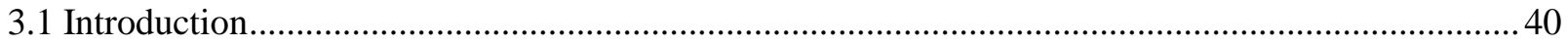

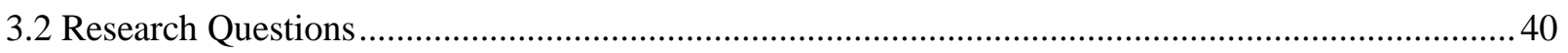

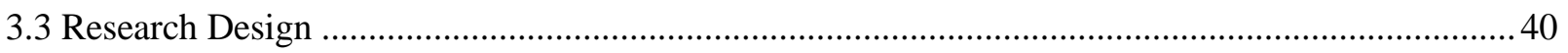




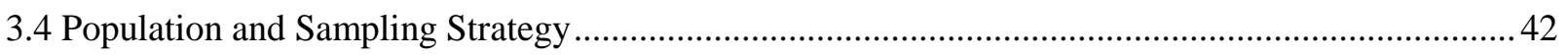

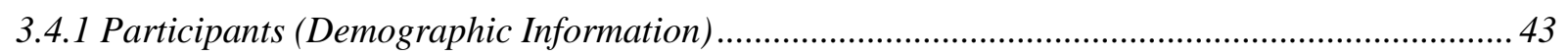

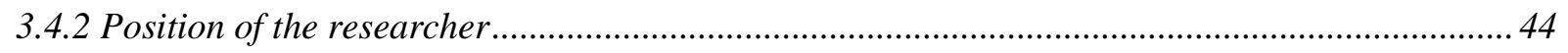

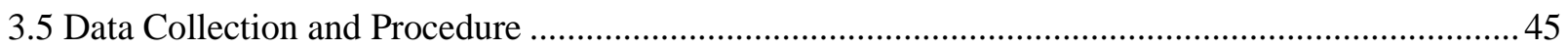

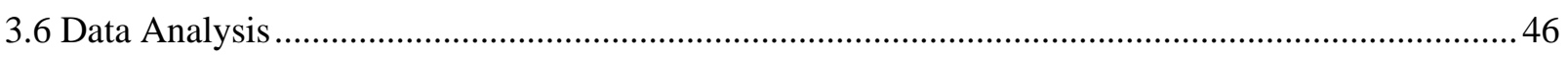

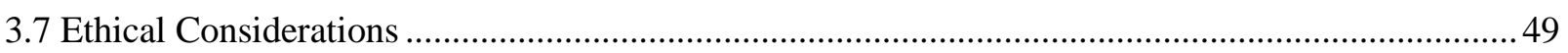

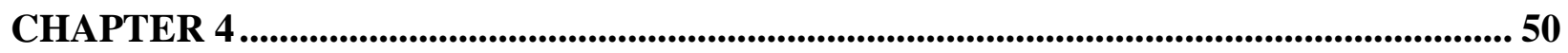

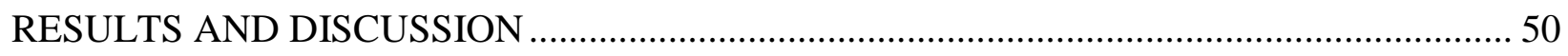

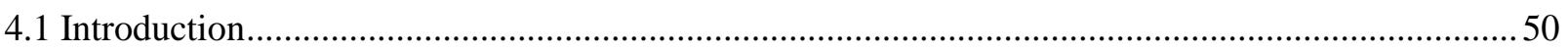

4.2 Navigating the interceptions between occupational identity and multiple identities .......................50

4.2.1 Navigating the intercepts of Personal and Occupational Identity ............................................51

4.2.2 Intercepting 'motherhood' in the workplace ............................................................................... 61

4.2.3 The construction of a gendered work identity............................................................................. 64

4.2.4 The deconstruction of ethnic identity in the workplace .............................................................. 66

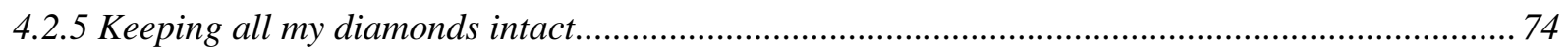

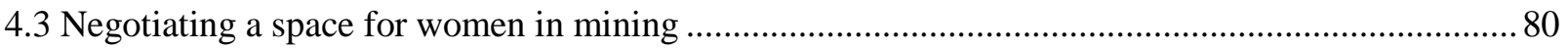

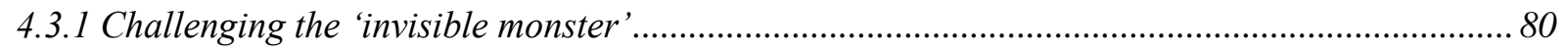

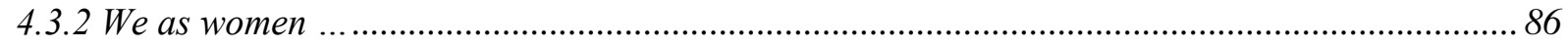

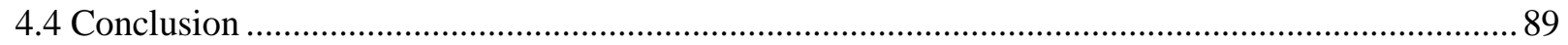

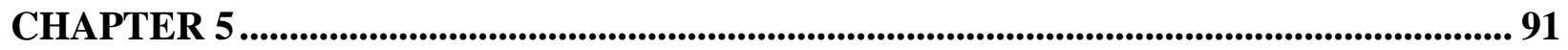

CONCLUSIONS, RECOMMENDATIONS \& LIMITATIONS ................................................. 91

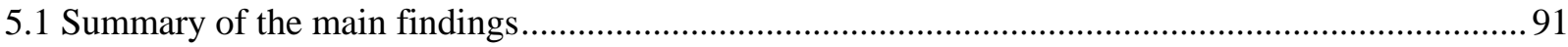

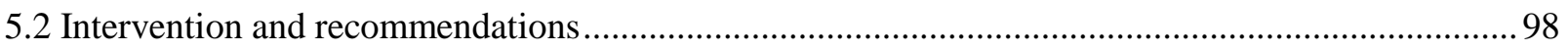

5.3 Limitations and recommendations for future research.............................................................. 99

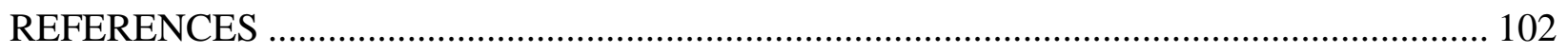

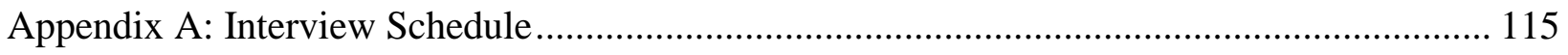


Appendix B: Ethical Clearance...

Appendix C: Permission Letter From Company X......................................................... 118

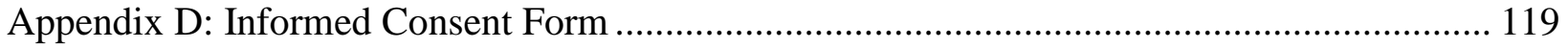




\section{CHAPTER 1 \\ INTRODUCTION}

"Never doubt that a small group of thoughtful, concerned citizens can change the world.

Indeed it is the only thing that ever has."

Margaret Mead

With the increasing proportion of women entering managerial positions within the mining industry (Botha, Fourie, Botha, Bischof, 2012; Lewis-Enright, Crafford and Crous, 2009), a historically male dominated environment in comparison with other industries (LahiriDutt and Macintyre, 2006; MMSD, 2001), it is important to explore the lived experience of women and acknowledge their impact in the workplace. In South Africa in particular, it is imperative to examine the ways in which women negotiate agency in their personal and occupational development within the context of often conflicting organisational policies, parameters, guidelines, indicators and legislative requirements. This research privileges the voices of women who are immersed in the contextual challenges of being women at work in the mining sector, so as to unravel the complexities and nuances of their lived experience and draw learning's which might be generic to the sector.

\subsection{Historical Context: Women in Mining in South Africa}

From a global perspective, the mining industry has historically been characterised by patriarchal tension. In the West, women have made more strides in terms of their integration within the industry, in contrast to developing countries, where women lag farther behind men in 
the workplace (Lewis-Enright, Crafford and Crous, 2009; Bolowana, 2005; Lahiri-Dutt and Macintyre). It is important to reflect upon the historical factors within South Africa which have shaped the gendered landscape of the mining industry today. Botha et al (2012) summarise the context for women in mining before the reformation of South Africa as a Sovereign Democratic State, which has served to shape women's representation in senior positions today:

(i) Legislation prohibited women from working in the mining sector, therefore

(ii) The selection of employees for mining positions was determined by race and gender, resulting in lower female representation; and

(iii) exclusionary legislation was given credence by the general attitudes and stereotypes in South African society

The democratic elections of 1994 led to the entrenchment of gender-equality as a Constitutional right (Republic of South Africa, 1996). Further, progressive legislation such as The Employment Equity Act (EEA, No 55 of 1998), The Preferential Procurement Framework Act (PPFA No 5 of 2000), The Broad-Based Black Economic Empowerment Act (BBBEEA No 53 of 2003), and The Labour Relations Act (LRA 66 of 1995) have opened new doors for the majority of the South Africans including women. In addition, legislation specific to the mining sector has been enacted in order to address the previous inequalities and disadvantages within this industry, viz. The Mineral and Petroleum Resources Development Act (MRPDA, No 28 of 2002) and The Broad-Based Socio-Economic Empowerment Charter for the South African Mining Industry (Mining Charter, 2002). 
The impact of the aforementioned reformations in legislation in terms of gender is evident in the subsequent increase in the proportion of women participating in the labour force (Statistics South Africa, 2011), the bulk of whom are African women (Van der Westhuizen, Goga \& Oosthuizen, 2007, cited in Mostert 2009). Despite the consequent and relative 'feminisation' of the workforce, it is of concern that little progress has been made in terms of integrating women into senior management structures (Botha et al., 2012; Lewis-Enright et al, 2009). Evidence of this is that "although women make up 52\% of the adult population, and have a $41 \%$ representation in the workforce, only $7 \%$ of South African directors are female, $3 \%$ of chairs of boards are female, and 2\% of CEOs are female" (Lewis-Enright et al, 2009, p. 136). The former South African president, Thabo Mbeki concurred: "South Africa still lags far behind in terms of actual implementation, particularly in mainstreaming gender issues" President Thabo Mbeki: State of the Nation Address February 2003. The focus of this research is thus on women in senior positions, categorised by the organisation as 'Supervisors', 'Superintendents' and 'Managers'.

\section{$\underline{1.2 \text { Constructions of gendered mining }}$}

In their book, Women Miners in Developing Countries: Pit Women and Others, LahiriDutt and Macintyre (2006) provide a vivid account of the gendered positioning of men and women within the mining sector:

“...mining provides us with powerful, visual and metaphorical images; it is gargantuan, dangerous, heroic and mysterious, involving destruction and penetration of the earth's surface... Images of mining as human endeavour incorporates the elements of physical strength, endurance 
and filth, all characteristics of "masculinised work" (Robinson, 1996, cited in Lahiri-Dutt and Macintyre, 2006, pg. 2).

By contrast, the wives of mine-workers have been recognised for their domestic contribution in supporting their heroic husbands who risk their lives in providing for the family (Lahiri-Dutt \& Macintyre, 2006).

How have these polarised representations of 'masculinised work' and 'feminised work' been constructed and sustained over time? Given the depiction of these roles as polarised and incompatible, what are the implications for women participating in a traditionally 'masculine' occupation? There are various theoretical perspectives that contend with such questions. For the purposes of this study, two frameworks, Social Constructionism and Post-Structuralism, have been invoked in order to examine such questions. These approaches are based on the belief that there is nothing outside of language, it is "what 'makes' or constructs our world... everything is constructed by the way we name it... our conscious and unconscious minds, our world, our histories and our values and morals are constructed by the words we use and the ways in which we use those words" (Holloway, Byrne \& Titlestad, 2001, p46). These words constructed in society become 'knowledge' or 'truth'. From a constructionist approach, knowledge cannot represent reality, as all realities are perspectival (Durrheim, 1997). However, Social Constructionism does not deny the existence of truths, but rather it holds that all 'facts' are a matter of perspective which can only emerge in the context of socially shared understanding (Durrheim, 1997). Foucault (1979) postulates that such constructions within society are a function of power dynamics in society. For Foucault, the subordination of women in relation to men is a function of complex and multiple force relations and those that are viewed as being the 
ones that are 'dominated' are as much a part of the network of power relations as the dominant group; it is invested in them and transmitted through them (Hoy, 1986). However, Foucault (1980) argued that power and resistance go hand-in-hand, to the extent that power cannot exist without resistance. "Power depends for its existence on the presence of a multiplicity of points of resistance and the plurality of resistances should not be reduced to a single locus of revolt or rebellion" (Banjeree, 2007, p. 108). In relation to the present study, an analysis of the power dynamics within participant's narratives, the resistance (agency) and reification of 'dominant' constructions of the self, as well as the implications for participants' sense of identity were examined.

Lahiri-Dutt and Macintyre (2006) ask a crucial question about how we construct our understanding of 'women in mining':

"Do we see women as victims of the ill-effects of mining on the community and suffering without agency, at best fit for soft serving jobs as 'secretaries and office clerks,' or do we see them as equal and productive partners in an empowering process of development?" (Lahiri-Dutt and Macintyre, pg. 4).

The use of the Constructionist approach is thus pertinent in giving voice to women from this study, and a platform to challenge the 'victim' position outlined above. In particular, this approach rests on a liberatory imperative in that, if the focus lies in subjective constructions rather than objective "truths", and if it is human beings who have built these constructions, then it is possible (theoretically) to construct the self in line with conceptions that may be more facilitating for us (White, 1998). 


\section{$\underline{1.3 \text { Study Aim }}$}

The aim of this study was to provide an account of the lived experience of women in senior positions in a mining organisation in KwaZulu Natal; to unravel the complexities and nuances in their lived experiences; and its impact on their various social roles.

\subsection{Research Questions:}

The specific questions investigated were:

1. How do women in mining narrate their experience?

2. What are the ways in which women live with the tensions of a workplace that is both liberatory and limiting?

3. What are the implications of these tensions for women's wellbeing and personal multiple social roles and identities?

\subsection{Demarcation of Chapters}

This dissertation consists of 5 chapters that form part of four major sections: an introduction (Chapter 1), a theoretical component (Chapters 2), an empirical component (Chapters 4 and 5) and a conclusion (Chapter 6). Table 1 is a summary of the demarcation and content of each of the chapters. 
Table 1 Demarcation and Content of Chapters

\begin{tabular}{|l|l|}
\hline CHAPTER & CONTENT \\
\hline Chapter 1: Introduction & $\begin{array}{l}\text { The reader is provided the historical context that has impacted the current day environment } \\
\text { for women in the mining sector. An outline of post-apartheid legislation in relation to women } \\
\text { in mining is provided. Gendered constructions within the mining industry are introduced, and } \\
\text { the reader is introduced to the aims and research questions investigated in this study. }\end{array}$ \\
\hline $\begin{array}{l}\text { Chapter 2: Literature Review and } \\
\text { Theoretical Framework }\end{array}$ & $\begin{array}{l}\text { A review of both international and national literature is presented in line with the core } \\
\text { constructs under investigation: Identity, Power and Agency. The two core paradigms used to } \\
\text { frame this investigation, Social Constructionism and Post Structuralism, are discussed. }\end{array}$ \\
\hline Chapter 3: Methodology & $\begin{array}{l}\text { The research methodology is described in terms of: Research Questions, Study design, } \\
\text { Sampling, Data collection method, Data Analysis and Ethical Considerations. }\end{array}$ \\
\hline $\begin{array}{l}\text { Chapter 4: Results and Discussion } \\
\text { Recommendations and Limitations }\end{array}$ & $\begin{array}{l}\text { A qualitative analysis of results is presented, integrated with a discussion framed by the } \\
\text { current empirical literature and selected theoretical frameworks. }\end{array}$ \\
\hline
\end{tabular}




\section{CHAPTER 2}

\section{LITERATURE REVIEW AND THEORETICAL FRAMEWORK}

\section{$\underline{2.1 \text { Introduction }}$}

This chapter is composed of two empirical components, a review of the literature in the context of gender and leadership; and an examination of the two core theoretical frameworks that employed in this study, viz. Social Constructionism and Post Structuralism. An account of the central assumptions within each approach is discussed in relation to the literature review. Finally, the relevance of the literature and the chosen epistemological approaches to the study's research questions is summarised.

\section{$\underline{2.2 \text { Literature Review }}$}

\subsubsection{The historical context of labour relations in South Africa}

South Africa transcended a difficult and turbulent labour economic history. Before the reformation of South Africa as a Sovereign Democratic State in 1994, (i) Legislation prohibited women from working in the mining sector, (ii) Employee composition was determined by race and gender, resulting in lower female representation; and (iii) Exclusionary legislation was given credence by the general attitudes and stereotypes in South African Society (Botha et al., 2012).

In contrast, the new constitution in post-apartheid South Africa has emphasised gender equality as a constitutional right for all South Africans. The provisions of the constitution in Chapter One state: 
"The Republic of South Africa is one sovereign, democratic state founded on the following values:

b) Non-racialism and non-sexism (Republic of South Africa 1996a)

Chapter two, section 9 of the constitution sets out the equality provisions among citizens:

S9 (3) The state may not unfairly discriminate directly or indirectly against anyone on one or more grounds, including race, gender, sex, pregnancy, marital status, ethnic or social origin, colour, sexual orientation, age, disability, religion, conscience, belief, culture, language and birth.

S9*(4) No person may unfairly discriminate directly or indirectly against anyone on one or more grounds in terms of subsection (3). National legislation must be enacted to prevent or prohibit unfair discrimination (Republic of South Africa 1996a)".

Based on the new constitution in South Africa, gender or sex discrimination is illegal. In addition, laws have been passed that are concerned with social transformation, and righting South Africa's legacy of discrimination and social exclusion in the workplace. Amongst these laws are:

- The Labour Relations Act (LRA, No 66 of 1995),

- The Employment Equity Act (EEA, No 55 of 1998),

- The Preferential Procurement Framework Act (PPFA No 5 of 2000),

- The Broad-Based Black Economic Empowerment Act (BBBEEA No 53 of 2003), 
Certain measures have been taken in order to address the previous inequalities and disadvantages specific to the mining sector:

- The Mineral and Petroleum Resources Development Act (MRPDA, No 28 of 2002) and,

- The Broad-Based Socio-Economic Empowerment Charter for the South African Mining Industry (Mining Charter, 2002) which expands on the social provisions of the MRPDA.

These laws stipulate that owners and managers of mines must:

- "enhance equity in the sector across employment and ownership categories;

- address the social impacts associated with mining; and,

- enable South Africans generally to benefit from the "exploitation of mining and mineral resources." (Section 100 (2)(a), MRPDA No 28 of 2002).

The MRPDA requires that by 1 May 2009, the mining industry include 10 percent of women in its workforce. The Mining Charter set targets in relation to socio-economic goals, known as the mining score-card, which incorporates reaching employment equity targets for women in mining. The targets were set for April 2009 and noncompliant mining companies were placed at risk of losing their mining licences. An assessment conducted in 2009 by the Department of Mineral Resources (DMR) revealed that little progress had been made in the transformation of the mining sector in terms of diversification of management and core-skilled workers (Botha et al., 2012). The result was a further attempt, spearheaded by the Broad-based Socio-Economic Empowerment Charter, launched in September 2010, to redress the inequalities and disadvantages in the Mining Sector. Although women's representation within the mining 
sector has still not reached its target of 10 percent, the changes in legislation has created an entry point for women to a sector that they were previously denied access to (Botha et al., 2012).

According to Mostert (2009) not much has changed in terms of gender-role expectations since the apartheid era. Therefore, it is not surprising that mining organisations have not yet reached the legislated targets. "Government may stimulate but not impose gender equality. Thus different discourses concerning gender relationships function side by side in society" (Volman \& Dam, 1998, p.530). Based on Foucault's (1980) conceptualisation of power, in particular his conceptualisation of a 'net-like' organisation, with individuals as 'vehicles of power', the power dynamic at the societal level (micro-physics) is still perpetuating gender inequality. The extent to which the micro and macro physics of power in South Africa has shifted in the minds of individuals can be estimated in the analysis of public discourse. This research is therefore relevant within the context of an increased focus on equality and addressing power differentials in gender relations. Within women's narratives, gendered norms that serve to perpetuate gender inequality were examined with the intent of developing strategies to counter such discourse within the minds of women in particular.

\subsubsection{The Dialectic of Women in the Workplace}

Notwithstanding factors such as enabling legislation, a societal drive for the promotion of equal opportunity, and the increased acceptance of the need to embrace diversity, women are still under-represented in senior positions in the workplace (April, Dreyer \& Blaas, 2007). Local and international research highlights some of the tensions experienced by women as a minority 
group, tensions which are inadvertently heightened by the political attention that their situation attracts (Booysen, 2007). The subsequent discussion highlights some of the recent literature concerned with women in senior positions in the workplace.

In contemporary society, many women are starting to view work as central to their lives, the basis from which to structure their lives and a means from which to attain independence, selffulfilment, achievement and social status (Haworth \& Lewis, 2005), as well as attaining fulfilment of economic needs, a sense of identity and opportunities to engage in meaningful relationships (Koekemoer \& Mostert, 2010). With work becoming a salient feature of personal and social identity, there is amplified pressure for individuals to perform (Lahiri-Dutt \& Macintyre, 2006). The dominant view of the 'ideal worker' is someone who enters a career shortly after graduating, who then advances through the hierarchical ranks of an organisation without career interruption's, devoting a significant proportion of time to an organisation and making substantial financial contributions to family life (William, 2000, cited in April, Dreyer \& Blaas, 2007). This notion has significant implications for women who aspire to executive roles. April, et al. (2007) highlight the challenges for South African women in adhering to this construction of the 'ideal' worker : "In South Africa, many women take breaks in their careers, work reduced hours, or otherwise contribute large amounts of time to caring for children and responding to family needs. They often do this mid-career, at precisely the time when the "ideal worker" is climbing the career ladder" (p. 53). In effect, these norms are indirectly discriminatory towards South African women. Lewis-Enright et al, (2009) refer to the conceptualisation of the "ideal worker" as a male model of work which serves to render women less equipped to enter senior positions due to less time at their disposal to work longer hours. 
Negotiating a balance between work and other requisite roles, work-life balance, has been identified as one of the major challenges faced by working women in South Africa (Mostert, 2010; Broadbridge, 2008; Booysen, 2007; Rowe \& Crafford, 2003)

In examining families where both partners are employed Doucet (2000) and Windebank (2001) found that the career role is still seen as the primary domain for men, while women are still seen as the primary caretaker of the home and children. Research which examines work-life balance are particularly relevant in highlighting the challenges women face in juggling the demands from various social systems (e.g. Mostert, 2009; Allen, Herst, Bruck \& Sutton, 2000; Eby, Casper, Lockwood, Bordeaux \& Brinley, 2005; Frone, 2003). Mostert (2009) examines the conflict between simultaneous demands from 'work' and 'home', referred to as work-home interference. By definition, work-home interference involves is 'a process in which a worker's functioning (behaviour) in one domain (e.g. home) is influenced by negative load reactions that have built up in the other domain (e.g. work) (Mostert, 2009, p 1). Various studies (Allen, et al, 2000; Eby, et al, 2005; Frone, 2003) have found that prolonged 'work-home interference' in both work and home domains may generate stress that has a negative impact on a women's sense of well-being (cited in Mostert, 2009). Mostert's (2009) findings from her study of 500 women from organisations across South Africa, indicated that work demands (work pressure and work overload) are related to ill health (physical ill health, anxiety, depression) and were attributed to work-home interference. On the other hand, home demands (home pressure and home overload) are directly related to home-work interference and to ill health. This highlights the bi-directional effect of demands from work and demands from home on women's health. 
Rowe \& Crafford (2003) explored the barriers to career advancement experienced by professional women in the investment banking industry. Their findings demonstrated that women with children are often forced to choose between a career and motherhood. The assumption being that some women are less interested in/able to attain career advancement due to the constraint this may place on their role within the family.

A South African study by Mamabolo, Langa \& Kiguwa (2002) which explored student perceptions of motherhood in relation to career aspirations and prospects, highlighted ambiguity and contradictions as to how young educated women positioned themselves in relation to the role of a mother and a 'career women. While these women viewed their career aspirations as a desirable mode of self-development, they simultaneously regarded the possibility of pursuing a career and being a 'good' mother as being problematic.

An added tension for women managing dual roles (mother, wife, career) emanates from a dominant psychological discourse which posits that the psychological well-being of children is greatly dependent on the quality of mothering received (e.g. 'good-enough mothering' in Finchilescu, 1995). According to Hook (2002) such theories place blame on mothers for any pathologies that children may develop (as cited in Kruger, 2006). From a social constructionist perspective, motherhood can be understood as a socially sanctioned role in that women are socialised into this role through prevailing social discourses which are largely supported by mainstream psychology and medicine (Kruger, 2006). 
Morrell \& Jewkes (2011) expand upon Kruger's (2006) perspective with reference to the social discourse that positions and reifies women's domestic role within the family, and particularly within the context of providing child care. These authors examine the role of hegemonic discourse in the perpetuation of gender biased role definitions of child rearing responsibilities. By examining gender bias in the provision of care in society, these authors posit that hegemonic discourse is internalised by both men and women, to the extent that many women are positioned, and position themselves as primarily responsible for child-care (good motherhood practice) whereas men are positioned, and position themselves as primarily responsible for protecting and providing for their families (good fatherhood practice). This perspective is particularly relevant to the South African context where only about half of children are supported financially by their fathers or see their fathers regularly (Lund, 2006; Madhavan, Townsend \& Garey, 2008). Researchers argue that the promotion of 'alternative masculinities' by way of gender interventions that deconstruct hegemonic constructions of 'motherhood' and 'fatherhood', may transform gendered practices of caring thereby freeing men from their hegemony, unlocking in them the desire to develop more equitable relations with their children and enhancing an equitable balance of child-care responsibilities across gender (Montgomery, Hosegood, Busza, Timaeos, 2006; Lund 2006; Morrell \& Jewkes, 2011; Madhavan et al, 2008).

According to Anderson (2004) particular organisational cultures, together with the discourses embedded in them, will encourage specific gender behaviours that in turn impact on individual gender identities. Individuals develop a tacit knowledge of how to "do" gender within particular contexts and adapt their performances accordingly and, most often automatically: “...as practices become delineated in particular spaces by specific codes and norms, one 
articulates one aspect of self-identity in one space" (Anderson 2004,p. 52). Power relationships also operate to influence individuals because certain gender identities will be considered more appropriate than others, and if individuals step outside these expected "hegemonic gender norms" (Lister 2008, cited in Anderson, 2004), their actions may be considered problematic and may be censored or disciplined by others. In this case, women who do not measure up to social norms are often subjected to harsh criticism. This is illustrated by the conflict of balancing the role of being a 'mother' and having a career. According to Gillespie (2003), motherhood defines the female gender identity, deviation from which is considered unfeminine or unhealthy. Most women become mothers at some stage in their lives, and the experience of having a child is for many, fundamental to the essence of a 'real' woman (Kruger, 2006). Based on the belief that motherhood is natural, desirable and rewarded with social approval and acceptance, it is considered the social norm for women to have children and provide childcare (Kruger, 2006). Accordingly, it is a widely entrenched belief that many women do not wish to 'sacrifice' motherhood for other roles, such as having a serious career (Richardson, 1993). Common perceptions of women who choose not to have children in favour of a career for example, are that they are selfish, unfortunate, psychologically flawed or unnatural, leading to social scrutiny and stigmatisation (Gillespie, 2003).

Another tension inherent within the South African context is the perception that women in the new South Africa have more opportunities and thus more economic power at their disposal than men (Booysen, 2007). This perception creates conflict as it is also associated with the belief that women have been appointed to certain positions as part of affirmative action initiatives 
rather than because they have the required skills, experience and/or qualifications (Cummings, 2004; as cited in April, Dreyer \& Blass, 2007).

A study conducted by Mather-Helm (2005) suggests that it is difficult for women to enter senior positions as the organisational environment is not yet ready to accept women as professional equals. This serves as a barrier to the emerging ideology which encourages and endorses women's employment as a desirable mode of self-fulfilment (Naidoo and Jano, 2002), i.e. women are encouraged to devote time, energy and effort towards career development for their own fulfilment, yet face the possibility that their work environment may restrict the extent to which such development takes place. With reference to these tensions, the aims of this study were to understand the positioning of women within senior positions in the mining industry, in particular how their lived tensions impact on their identities, and how they negotiate agency within this context.

On the other hand some research emphasises the positive outcomes for women occupying prominent roles, both at home and in the workplace (dual roles). For example, a local study by Naidoo and Jano (2002) revealed a significant positive correlation between dual-role women's commitment to work and the home and family, indicating that dual roles could be complimentary rather than conflicting. It is interesting to note, however, that the sample selected (married women managers) were found to participate significantly more in their work role than their family role. Another finding by Barbee, et al (2010), identified the inherent advantage women have in coping with work-life demands in comparison with men. Results from Barbee et al's (2010) study indicate that feminine traits such as nurturance and emotional expressiveness, 
facilitates the acquisition and provision of social support for and by women; whereas normative masculine traits, such as an achievement orientation, autonomy and emotional control, makes it difficult for men to seek and obtain social support.

Executive women are an emerging group in South Africa, and decisions they make about how they balance work-life roles has implications for existing social norms in society: "Shifting norms mean that individual choices must be evaluated as society gives more opportunities for women to make choices about their future" (Mostert, 2009, p.11). Therefore, the greater proportion of women entering the work-place, and the mining industry in particular, creates opportunities for women to challenge existing cultural norms. According to Koekemoer \& Mostert (2010), there are only a few qualitative studies which explored the specific ways in which employees experience the interaction between work and personal life in the South African context. This underscores the need to explore how women position themselves within an increasingly competitive global market and how they negotiate ambiguous and contradictory gendered roles and practices.

Much of the research in work-life balance has been based on three theories: role theory, role conflict theory, and spill over theory (James, 2009). These theories focus on conflict (loss) and enhancement (opportunity) in maintaining career and family balance (Ibid, 2009). Role theory examines conflict between multiple roles, where each role is considered separate. This theory fails to consider how roles may interact positively. Similarly, role conflict theory examines how competing demands arising from multiple roles causes conflict, to the extent that individuals are forced to choose the role/s to which they want to ascribe precedence. By contrast, 
spill-over theory assumes that work may have a positive impact on home-life. With reference to the literature reviewed outlined above, it is evident that work has the potential to intersect and interact both negatively and positively with home-life, and vice versa, at different times over the life course. Tiedje et al. (1990) offer a perspective that combines role theory, role conflict theory and spill-over theory - the high conflict and high enhancement perspective. This perspective suggests that work life has the potential for both high conflict and high enhancement in interaction with home life and home roles at different times.

In contemporary society there has been a paradigm shift in the conceptualisation of an effective leader. "Top down, autocratically directed, rigidly hierarchical, fear generating organizations are giving way to something new" (Pranit, 2010, p248). Organisations are now encouraging employees to adopt a Transformational Leadership Approach (Ristow, Amos \& Staude, 1999; Bryman, 1996; Grobler, 1996). The Transformational Leadership approach involves adaptable team players and a flat organisational structure as opposed to rigid individual leaders within a hierarchical structure (Pranit, 2010; Ristow et. al 1999). In line with this approach, Daft (2005) argues that women are more willing than men to share power and information, emphasise employee development, and work toward enhancing others feelings of self worth (p.438). Further, Daft posits that men may become less powerful in organisations where women hold key positions, as women tend to lean towards building a more equitable work environment. A meta-analysis by Kellerman and Rhode (2007) revealed that leadership styles are gendered. Women demonstrated more democratic leadership and men were autocratic and taskoriented. Ayaman and Korabrik (2010) highlight the way in which the image of leadership has evolved over time in that there has been more recognition of the importance of people skills in 
relation to task-skills for leaders. The new leadership approach, referred to as transformational leadership, focusses on the salient role that 'people skills' play in motivating and inspiring teams towards the vision of the organisation, and hence greater productivity, and hence greater effectiveness as a leader (Bryman, 1996). Ayaman and Korabrik (2010) assert that the increased prominence of the transformational leadership paradigm is associated with the move toward the inclusion of more women in the workplace and the subsequent 'feminisation of leadership'. This has given rise to the promotion of a more androgynous approach to leadership.

Similarly, South African studies have also alluded to shifting gendered norms within the workplace; for example Mphokane (2008) examined the perceptions of what constitutes a "successful manager" held by male and female managers in the coal mining industry. The results indicated that the majority of research participants, both male and female, outlined the characteristics of a "successful manager" to be more androgynous as opposed to being more 'masculine'. Eagly and Karau (2002) posit that a more androgynous conception of leadership, which emphasises equal importance of task and people skills, will open up more opportunities for women to be considered as leaders and will assist them in negotiating the barriers prevalent in the workplace and society. Ayaman and Korabik (2012) posit that "an examination of the effects of gender and culture has the potential to change our definition of what constitutes leadership and what is considered to be effective leadership. This more inclusive conceptualisation can expand the vision of leadership to represent all human beings" (p. 167). 


\subsubsection{Relevance of the literature to this study}

The historical context of labour relations (macro-politics) in South Africa is critical in the analysis of women's narratives, specifically in the mining sector as it is within this context that women's current roles, behaviours and identities have emerged. Further, the literature examined reveals the diverse, dynamic, ambivalent and hybrid range of experiences women are facing in contemporary society today. The tensions implicit in these experiences will be examined and expanded upon with reference to the lived experiences of the women participants in this study.

Implicit in the literature review is the link between current organisational practices in relation to gender, and the challenges women experience. The practices identified in the literature reflect elements of the dominant 'masculinised' identities and role descriptions remnant from the apartheid era. The literature also reveals that despite prevailing ideologies and practical challenges, some women have demonstrated agency in negotiating a space for themselves as equal actors in the workplace as well as simultaneously balancing dual-role demands. Such agency serves as a powerful force which challenges the dominant hegemonies in South African society. From a Foucauldian perspective, this dynamic within the micro-politics of the society has a productive function in the formation of alternative narratives that challenge existing ideology around gender equality. The extent to which this prevails, in this case study, is explored through the voices of the women participants in this research. 


\subsection{Theoretical Framework}

A Social Constructionist and Post-structural framework has been selected in order to explore multiple identities of participants across space and time, and explore the ways in which multiple alternative perspectives co-exist with their experience of dominant ideologies.

\subsubsection{Social Constructionism}

Social constructionism is generally understood as anti-essentialist and anti-realist (Burr, 1995), that is, knowledge cannot represent reality, as all realities are perspectival (Durrheim, 1997). However, this approach does not deny the existence of truths, but rather it holds that all 'facts' are a matter of perspective which can only emerge in the context of socially shared understanding (Durrheim, 1997). As Gergen (1999) points out, "For the constructionist, all claims to knowledge, truth, objectivity or insight are founded within communities of meaning making - including the claims of constructionists themselves" (p. 2). In essence, Social Constructionism is comprised of a multitude of overlapping perspectives which can collectively be defined as a form of resistance against the dominant and institutionalised Modernist paradigm (Ibid, 1999).

Social constructionism advances several key assumptions. The world and (knowledge) is considered to be interpreted by the observer through human experience that is to the greater extent influenced by language (Burr, 1995). Categorisations of knowledge are represented in linguistic terms and these categorisations emerge from the social interactions within a group of people at a specific time and place. Thus, knowledge can be thought of as being situational, 
historical and culturally specific (Burr, 1995; Durrheim, 1997). Given that the use of language is derived through social interaction that is located in time and place, meaning is specific to a particular context and can thus fluctuate over time. Social constructionists maintain that meaning is produced through a reflexive process (Durrheim, 1997), i.e. in collaboration, people constantly create and change narratives and are themselves created and changed by these narratives. In addition to this, social constructionists argue that the way in which reality is understood at any given point in time is determined by the 'status' given to that particular knowledge within that particular time and context (Burr, 1995). Thus, knowledge is created and sustained through social interaction. For Foucault, when particular knowledge constructions are denoted 'status' over others, they are then given 'truth' status (Foucault, 1980). These truths are given a privileged status and are as such deemed universal in their time.

In line with social constructionist epistemology, this study examined how women's narratives are created through dialogue and what narratives these women use to make sense of their worlds. The role of narratives is to provide a framework of meaning in which human experience is organised (Epston, White and Murray, 1992). These experiences are often interpreted through the existing dominant narratives which are meaningful to the individual (White, 1991). However, in addition to the dominant narrative there also exist "alternative stories" that, though less established, might in fact be preferred by some individuals over the dominant views (White, 1991). The conflict lies in the power dynamic between the dominant and alternative stories in giving meaning to an individual's life, and how these narratives define the individual's identity. Lax (1994) describes the narrative as "the process of defining who we are in interaction with other people's perceived understanding of us. This is a recursive process. We 
reveal ourselves in every moment of interaction through the on-going narrative that we maintain with others" (p.71). As the focus of this study was to elucidate participants' experience of their environment and the implications for their gendered identities, a social constructionist paradigm was considered appropriate because it steps away from traditional assumptions that identity is fixed and essential. Further, this approach offers a broader lens within which a more complex dyad of subjectivities and reflexive processes may be explored.

From a constructionist perspective, a person's sense of reality and self are sustained through stories which are narrated about the self and the world. The self does not exist in a static or singular way within the individual, but "is the process of developing a story about one's life that becomes the basis of all identity and thus challenges any underlying concept of a unified or stable self" (Lax, 1994, p. 71). Such an approach is based on the idea of constructive alternativism, i.e. there exists an infinite number of constructions of events. The focus therefore is placed not on some objective reality but upon different meanings within which our worlds become invested (Burr, 1998). This approach thus rests on a liberatory imperative in that if the focus lies in subjective constructions rather than objective "truths", and if it is human beings who have built these constructions, then it is possible (theoretically) to construct the self in line with conceptions that may be more facilitating for us (Ibid, 1998). Personal narratives present opportunities for individuals to take on ways of being in line with their own personal preferences. In contrast to "internal states" of identity (an essentialist notion), White (2001) focuses on "intentional states of identity" to reveal how hopes, values and commitments shape and affirm agency in terms of preferred ways of being (p. 11). The advantage of this research is highlighted by White (2001) in that by helping individuals map the historical development of 
their identity, they are able to appreciate the agency they have in shaping preferred ways of being.

The individual interviews conducted in this study were based on conversations with participants that were loosely framed by interview questions. Anderson and Goolishian (1992) defined conversation as "any interaction between people in which there is some shared space and mutual interaction within this space" (p.26). In line with social constructionist epistemology, the conversation is a reflexive process. According to Lax (1994), reflexivity in the research context involves a process in which participants become aware of their own stories, thereby becoming an object of their own observation. This enables participants to make shifts in their own perspectives, view themselves from a different perspective, and question the meaning of their

own descriptions of themselves. This allows for participants to take agency in the construction of themselves in relation to others. Thus, the research not only investigates the current perspectives held by participants, but enables participants the space to reflect upon their own subjectivities, and alter their self-narrative that may be more facilitative for them as actors in their own contexts and roles.

\section{i. $\quad$ Social Identity}

Social Identity Theory provides a useful framework for conceptualising how an individual's membership in various social groups shapes their perspectives and experiences in different contexts (Tajfel \& Turner, 1986). Tajfel (1972) defines social identity as "the 
individuals knowledge that he/she belongs to certain social groups together with some emotional and value significance to him/her of the group membership" (cited in Hogg \& Abrams, 1990).

Tajfel \& Turner (1986) posit that social identity acquires significance through comparisons between groups when status differences between such groups are salient. How positively a group member perceives his or her group in relation to other relevant groups determines the adequacy of the individual's social identity in a given setting. Because people generally want to maintain a positive self-image, those in groups with low status may engage in group- and self-enhancing strategies (Tajfel \& Turner, 1986)

The limitation of Social Identity theory is its primary emphasis on within-group effects of social comparisons, resulting in a tendency to overestimate differences between groups and under estimate differences within groups (Brehm, Kassin and Fein, 2005), resulting in the emergence of social categories in society. Social categorisation is the precursor of the emergence of stereotypes within society. Stereotyping involves attributing an opinionated characteristic to a social group or its members which, when negative, constitutes prejudice (Ibid, 2005). Stangor and Schaller (2000) highlight the way in which stereotypes are approached, transmitted and changed through various sources of cultural practices. From a cultural perspective, there is evidence suggesting that stereotypes are perpetuated through language, the media, social norms and roles (Ibid, 2000). 


\section{ii. Occupational Identity}

Saayman \& Crafford (2011) summarise the fundamental elements of work: it is central to adulthood; it is the thread that is weaved into individuals sense of self and subsequent identity; it offers success, status, power, financial security, learning, mental stimulation, self-fulfilment and the attainment of knowledge. Considering these factors, work forms a fundamental part of an adults lived experience, and a space in which to internalise such experiences in the discovery and construction of identity. As such, occupational or work identity can be conceptualised as a social identity (Ibid, 2011).

One of the most comprehensive definitions of occupational identity, that incorporates elements of Tajfel and Turner's (1985) conceptualisation, was postulated by Walsh and Gordon (2007) "[work identity is] a work-based self-concept, constituted of a combination of organisational, occupational, and other identities, that shapes the roles individuals adopt, together with the corresponding ways in which they behave when performing their work in the context of their jobs and/or careers (p.2, cited in Lloyd, Roodt \& Odendaal, 2011).

Given the multiplicity of roles women occupy, including the work-role, it is self-evident that it may lead to a sense of dissonance and incoherence. In negotiating their work identity, women need to navigate between often conflicting demands and tensions that construct and position their sense of identity (Saayman \& Crafford, 2011). Therefore, Social Constructionism, and social identity theory, provides a platform from which to investigate the tensions and demands that allow the women participants in this study to negotiate their work identities. 


\section{iii. $\quad$ Gendered Identity}

From a social constructionist perspective, gendered identity cannot be viewed as a simplistic definition of what one is, but rather as an active reflexive process of practices given meaning within social interactions. Thus, gender is an accomplishment: "the activity of managing situated conduct in light of normative conceptions of attitudes and activities appropriate for one's sex category" (West \& Zimmerman, 1987, p. 127). For West and Zimmerman, "doing" gender is not simply about conforming to stereotypical gender roles - but involves active engagement in any social practice that may be conceived as gendered. The present study adopts the view that gender roles cannot be separated from the historical, political and social context in which it has evolved, and been shaped and negotiated over time.

The formation of gendered identity is concerned with how individuals link their interests, behaviours and psychological characteristics to their internalised notions of masculinity (socially constructed characteristics of men) and femininity (socially constructed characteristics of women) that are usually prescribed by society (Lahiri-Dutt \& Macintyre, 2006). Historically, mine work has been socially constructed as dirty, heavy and risky and as such deemed unfit for women (Ibid, 2006). However, these historical images have become less prevalent in modern day mining due to technological advancements and diversification of the types of jobs now available in this sector (Ibid, 2006). Therefore, a tension exists between traditional notions of mine work and actual practices in the workplace.

In relation to Social Identity theory, women's gender identity is considered one aspect of their social identity; it is the meaning women attach to their membership in the category 
"female." Identification with this category can be associated with positive, negative, or ambivalent feelings, depending on the salience and nature of comparative distinctions between men and women in a given setting (Ely, 1995). These distinctions and the value attached to them in turn affect women's group- and self-attributions, including stereotypic attributions. These processes of comparison and attribution, as they occur in organisational settings, help to shape women's gender identity at work (Ely, 1995).

\section{iv. Ethnic Identity}

Verkuyten (2005) conceptualises the lineage of ethnicity along two dimensions, circumstantial and primordial. The circumstantial dimension highlights that there are ideological pressures within society that structure, legitimise or influence the manifestation of ethnicity, based upon power relations. The primordial dimension of ethnicity, on the other hand, illustrates the emotional aspect of ethnic identities, as they provide individuals and groups with meaning through solidarity, a sense of belonging and kinship. This emotional aspect and related sense of belonging is directly linked to the development of social identities within social identity theory, in that individuals identify with certain social groups and obtain a sense of belonging through the emotional significance of their group membership (Hogg \& Abrams, 1990). Therefore, in articulating social identities, the potential for agency and resistance of alternative identities develop (Duveen, 2001). In this regard, the genealogy of ethnic identification is linked to ideological pressures which assist individuals as agents in making sense of their identity and group membership (Verkuyten, 2005). 


\section{v. Collective Identity}

In contrast to social identity, collective identity is a collaborative and shared definition that is constructed and negotiated by a group of individuals, signified by common interests, experiences, and solidarity (Melucci, 1989). The construction of collective identity is influenced by a group dynamic composed of individuals perceptions of issues, and how the group collectively views them, which becomes the basis for their "weness" (Melucci, 1989) Polletta and Jasper (2001) add to Melucci's definition of collective identity as: "an individual's cognitive, moral, and emotional connection with a broader community, category, practice, or institution" (p. 285). These authors highlight collective identity as a 'mobilizing identity' that might contribute to sustaining women's agency. According to Bradley and Healy (2008) however, multiple identity affiliations (e.g. class, race/ethnicity, sexuality) may create ambiguity about who 'we' are and who 'they' are, leading women to question the salience of gender as a mobilizing identity.

\section{vi. Identity and Agency}

The notion of agency, within the context of this study, has been conceptualised with reference to how women negotiate their ever-changing identities in relation to social as well as individual pressures and circumstances. This study adopts Ronald Inden's (1990) definition of agency conceptualised as "the realized capacity of people to act upon their worlds and not only to know about and give personal or intersubjective significance to it. That capacity is the power of people to act purposively and reflectively, in more or less complex interrelationships with one another, to reiterate and remake the world in which they live, in circumstances where they may 
consider different courses of action possible and desirable, though not necessarily from the same point of view" (p. 23).

However, agency has its limitations because individuals negotiate their sense of self within a social field which is not controlled by one individual, but all individuals and identity negotiation is formed outside and inside of the self. Despite this, Holland, Lachicotte Jr, Skinner and Cain (2001) posit that agency can be viewed as a creative endear of arranging the discoursed and practices available, but in a time and space defined by others.

Identity is considered to be a key aspect of agency. Within the social context, people position themselves within particular discourses prominent in society, either with or without agency (Lewis-Williams, 2001). From a collectivist perspective, agency can be increased amongst marginalised groups if there is a strong sense of collective identity, given that these identities do not constrain their ability to exercise agency (Durie, 1999). When people are marginalised by existing discourses, their agency decreases (Jordan and Weedon, 1995). Within collective identities, agency is exercised in how individuals participate in constructing these collective identities (Davies, 2000). Yuval-Davis (1993) recognized that engaging in the collective requires "keeping one's own perspective on things while empathizing and respecting the others as well as being open to change and growth as a result of the encounter" (p. 11). The present study will examine the collective perspectives identified within women's narratives and how women work together to determine policies concerning women. People are either "active subjects who take up positions from which (they) can exercise power within a particular social practice or (they) are subject to the definition of others" (Jordan and Weedon, 1995, p.11). In this 
study, identity and agency was conceptualised and elaborated through an examination of the meanings and interpretations that women express in terms of the extrapolation of their identities and agencies over time and space.

Given its apartheid legacy, South Africa is in so many ways an ideal setting for an interrogation of the notion of identity. Dominant discourses around racial, cultural and gender identities, historically constructed by the apartheid project, are constantly evolving in postapartheid South Africa, in a veritable public contestation to re-define and unravel the manifest racial, ethnic and gender character of the peoples of the country (Gounden, 2010). Present identity conflicts in South Africa emerge as these various and shifting identities seek to assert and re-assert themselves in the context of a multicultural pluralistic post-apartheid society (Ibid, 2010). In light of the tensions highlighted around the multiple roles women now occupy and the changes in gender roles in South African society, there is a palpable need to reflect on the conceptualisation of identities of South African women. Mama (1995) argues that a diverse society like South Africa requires people to inhabit a space of multiplicity characterised by comfort with ambiguity, dissonance, hybridity and difference. This is precisely the vantage point in which this study is located.

\subsubsection{Post Structuralism}

Social Constructionism and Post-structuralism are ontologically similar, both emphasise that reality is socially constructed and multiple. From an epistemological standpoint, both frameworks reject modernist assumptions of universalism and essentialism (Michael, 1999). 
Post-structuralism constitutes a diverse range of theories, the basic tents of which emphasise individual consciousness, social meaning and organisation as being constituted within language (O'Brien \& Penna, 1998). Inherent in poststructuralist theory is the understanding of language as plural and shifting, where narratives give rise to a representation of reality, not ultimate truth (Ibid, 1998). For Foucault (1984) "post-structuralism involves a critique of metaphysics: of the concepts of causality, of identity, of the subject, of power, knowledge and truth" (p.108). Foucault expands upon post-modernisms rejection of metanarratives as ultimate truth, by explicating the role of institutional power which serves to marginalise certain discourses in favour of that of the dominant cultural group within society, i.e. metanarratives are legitimated through institutionalising power. Foucault (1979) proposed that people come to regulate themselves through the internalisation of cultural prescriptions. What might seem to be freedom on the surface may be a form of compliance whereby citizens restrict their life choices to fit socially sanctioned options. Transformations occur when people are reflective of what is being told to them about the self and others. Being defined by someone as "other" than they deem accurate or congruent with their own narrative is a violation (Hooks, 1989). Foucault outlines a notion of 'discursive resistance' as a form of agency. This involves the emergence of multiple subject positions as alternatives to the dominant discourse (Caldwell, 2007). Foucault argues for discursive resistance as a positive productive force, rather than simply a negative counter reaction (Ibid, 2007). "For Foucault, discursive resistance is ultimately a volitional act of refusal; it allows those who are 'subjects' of power to act otherwise and reject their confinement and selfsubjugation within pre-determined discourses of power/knowledge" (Caldwell, 2007). 
A key tenet within the post-structuralist and social constructionist schools of thought is the assumption that all ways of understanding are embedded in and seen as products of the historical and cultural context within which they are located (Burr, 1995). This perspective gave rise to the possibility for individuals to construct multiple realities through social dialogue, making social dialogue a legitimate object of psychological investigation (Durrheim, 1997). In particular, this study focused on women's narratives about the specific practices and behaviours they enact within their multiple roles as women, and the extent to which they have been socialised to embody and accept these roles as normal and natural.

\section{i. Power}

Foucault's conceptualisation of power differs from previous traditional conceptions within the social sciences in three distinct ways (Banjeree, 2007). Firstly, he does not conceive power as something that can be possessed by a particular class or by the state, but rather as a strategy that is viewed more in terms of particular "manoeuvres, tactics, techniques and functioning's". Secondly, a relation of power does not place an obligation or prohibition upon the "powerless", power is much more complex than this as it invests in them and is transmitted through them. The first two points are fundamental to Foucault's conceptualisation as they imply that power is not something that can be possessed, it is not an institution of domination by a certain class or by the state on those that are 'powerless', however power is a 'complex strategic situation' and implies a 'multiplicity of force relations' (Banjeree, 2007). In other words, those who are viewed as being the ones that are 'dominated' are as much a part of the network of power relations as those who are perceived to be powerful (Hoy, 1986). Finally, Foucault argued 
that power and resistance go hand-in-hand, and thus "where there is power there is resistance", and that furthermore power cannot exist without resistance. "Power depends for its existence on the presence of a 'multiplicity of points of resistance' and this plurality of resistances should not be reduced to a single locus of revolt or rebellion" (p. 77).

Foucault posits that power should not be analysed as belonging to a particular individual, group or class, given that it is neither a commodity nor a possession. Instead Foucault (1980) advocates that "power must be analysed as something which circulates, or rather as something which functions in the form of a chain, it is never localised here or there, never in anybody's hands, never appropriated as a commodity of piece of wealth. Power is employed and exercised in a net-like organisation. And not only do individuals circulate between its threads; they are always in the position of simultaneously undergoing and exercising this power. In other words, individuals are the vehicles of power, not its points of application" (p. 98).

From this perspective, Foucault argued that the analysis of power should be initiated from the bottom-up. This is implicit in Foucault's previous prescription, in that if power is viewed as 'net-like', the analysis of power cannot precede in a top-down fashion, as what is important is the conduit points of power that make up the net-like organisation of power. "Hegemonic forms or global forms of power rely in the first instance on those 'infinitesimal' practices, composed of their own particular techniques and tactics, which exist in those institutions on the fringes or at the micro-level of society (within the family, the classroom, and so on)", thus Foucault focuses on the 'micro physics' of power (McHoul \& Grace, 1993, p. 90). The analysis of power within the apartheid context, for example, was both an incorporation of micro-politics and macro- 
politics. According to Hook (2004) macro-politics refers to those larger structures of power such as the state, whereas micro-politics refers to the functioning of power at lower and more decentralised levels; what Hook further argued is that both types of politic work together.

In relation to the present study, participants narratives and the meanings that they articulate are viewed as products of a dynamic inter-relationship between the socio-political (macro-physics) and the direct context in which participants are embedded (micro-physics). This literature review has provided a snapshot of the transformation of South Africa from the apartheid era to a democratic republican state based on a constitution which has entrenched rights of equality. The literature also revealed evidence that, despite the reformations that have occurred within the macro-politics of South African society, there still exists a remnant, yet dominant ideology from the apartheid era within micro-political spheres, such as the workplace, which edifies skewed power relations. This gives credence to Foucault's position that power cannot be seen as held within the macro-sphere and exerted upon the micro-sphere, but rather occurs through a network of simultaneous and co-existing interrelations between macro and micro politics. Within the context of the mining sector, such a perspective is fundamentally liberatory, in that knowledge emerging from participants lived experience and social interactions within Company $\mathrm{X}$ (and indeed within the research process), carries the potential of multiple resistance to orthodox notions of power as status-quo. In particular, the analysis of the microphysics of power was examined in this study through identity negotiation discussions among women in Company $\mathrm{X}$ in South Africa. Resistance to dominant norms within society are viewed as a form of agency in modifying the power dynamics at the micro-macro level. 


\section{ii. $\quad$ Gender and Power}

Ayaman and Korabik (2010) highlight the multifaceted nature of gender, incorporating 'intra-psychic' facets such as gender schemas and stereotypes; gender-role identity; gender-role traits, attitudes, and values; relationship dynamics between men and women and the social roles they are expected to, and often do enact in society. Traditionally, men's higher social status within society, and particularly in the mining industry, affords them with greater access to power, resources and privilege than women (Ibid, 2010). Thus, gender is both "a hierarchical structure of opportunity and oppression as well as an affective structure of identity and cohesion" (Ferree, 1995, p. 125). The analysis of identity is therefore inextricably linked to power.

Joireman (1997) proposes three types of relational orientations which relate to the way in which individuals assert power in order to achieve certain outcomes: prosocials, individualists, and competitors (cited in Maroda, 2004). "Prosocials tend to maximize outcomes for both themselves and others (i.e. cooperation) and to minimize differences between outcomes for themselves and others (i.e. equality); individualists tend to maximize their own outcomes with little or no regard for others' outcomes; and competitors tend to maximize their own outcomes relative to others' outcomes, seeking relative advantage over others" (Maroda, 2004, p.430). Research indicates that women tend to assert power in ways that help others, whereas men tend to assert power to pursue their own individual ambitions (Ibid, 2004).

Caution needs to be exercised in the application of the social constructionist and poststructuralism approach. There is a strong critique that likens postmodernism to intellectual nihilism (Butler, 1994). Many post-modern writings do not move beyond deconstruction, with 
claims that the 'unreal' has replaced the real. At this extreme, such a theoretical position may serve to undermine the legitimacy of the claims of the oppressed, positing that such oppression only exists in the minds of such individuals as a subjective experience (Lewis-Williams, 2001). This position is at risk of being appropriated by neo-liberal capitalist interests and discourses emphasising negative freedoms, (Lewis-Williams, 2001) thereby perpetuating capitalist, white male dominance.

Notwithstanding these cautions, postmodernism has several important contributions to make toward this investigation. It enables people (including research participants) to experience and reflect on processes of change, shifting roles, group memberships and sometimes statuses (O’Brien \& Penna, 1998). Additionally, post-modernism's pluralistic inquiry into subjectivity and identity (beyond metanarratives) widens the analysis on how ethnic, gender and class cultures both mediate and are mediated by dominant social structures of capitalism (Rosenau, $1994)$.

\subsubsection{Theoretical Relevance to the Present Study}

In examining how women within Company $\mathrm{X}$ narrate their experience, this study adopts a Social Constructionist view that women do not merely internalise gender roles as they grow up but they have agency in constructing and inferring meaning into their own subjectivities in reaction to changing norms in South African society. These theoretical approaches look beyond categories and examine the junctures between multiple identities, and the blurring of the boundaries of essentialist categories. The way in which women live with the tensions within a 
context of diversity, multiplicity, ambiguity, hybridity and difference, are examined with reference to post-structuralist notions of power relations and agency dynamics within the macro and micro-sphere of the mining industry. 


\section{CHAPTER 3 \\ METHODOLOGY}

\subsection{Introduction}

This chapter outlines the research questions for this study, describes the sampling methods used and provides a brief background history of the participants. The data collection procedure and data analysis methods are then presented, followed by an account of the ethical considerations adhered to in this study.

\subsection{Research Questions}

The aim of this study was to provide an account of the lived experience of women in senior positions in a mining organisation in KwaZulu-Natal. The specific questions investigated were:

1. How do women in mining narrate their experience?

2. How do women negotiate the tensions of a workplace that is both liberatory and limiting?

3. What are the implications of these tensions for women's wellbeing and personal, relational, community, and cultural identities?

\section{$\underline{3.3 \text { Research Design }}$}

Large studies on identity tend to rely on quantitative methods of research for practical reasons, including resource considerations and potentially generalisable results. The limitation of such studies is that research often ends up being descriptive and reifying, rather than explanatory 
(Liedle, 2008). For this study, a qualitative methodology was adopted in order to shed light on the 'how' 'why' and 'what for' in identity construction.

In line with the Social Constructionist epistemology, an ethnographic research approach was selected for this study. Stewart (1998) outlines four key characteristics of ethnographic research, which have been incorporated into the design for this study: participant observation, holsim, context sensitivity and socio-cultural sensitivity. Firstly, participant observation involves a joint collaboration between the researcher and the participants of the study within their natural environment. From this 'joint collaboration' the researcher's role in the enquiry is highlighted. In this study, research interviews were conducted on-site at Company X. In line with social constructionist thought, it is recognised that people come to create an understanding of who they are by talking and co-constructing their ideas of the self through narrative with others (Lax, 1994). The researcher's role in interacting with participants in establishing meaning is critical in the process, and is acknowledged as a critical part of this research. The concept of Holism adheres to the social constructionist argument that individuals' knowledge does not develop within a vacuum, but rather, is seen to emerge in the context of socially shared understandings. From a holistic perspective, knowledge can be thought of as being situational, historical and culturally specific (Durheim, 1997). Therefore, this study acknowledges that while meaning is derived within the socio-political context of South Africa (macro-politics), it is further developed, sustained and transformed through social interactions within the context of Company $\mathrm{X}$ and the local communities (micro-politics) (Hook, 2004). The third characteristic of ethnographic research, which follows from the first and second, is Context-Sensitivity. This involves making linkages between emergent concepts within the micro-politics and the macro- 
politics of society. These connections were explored through a Foucauldian understanding of power: "Power is employed and exercised in a net-like organisation. And not only do individuals circulate between its threads; they are always in the position of simultaneously undergoing and exercising (Foucault, 1980, p.98). Within the context of mining, such a perspective is liberatory, in that knowledge emerging from social interactions within Company $\mathrm{X}$ and indeed from the research process, is a form of power that has the potential to challenge the status-quo. The final characteristic of ethnography is socio-cultural sensitivity, which is defined as a "detailed depiction and analysis of social relations and culture" (Wolcot, 1992, cited in Stewart, 1998, p. 7). In depicting the social relations and culture of participants within Company $\mathrm{X}$, careful attention was paid to linking participants narratives to macro and micro politics as explained above; situating quotes from participants in relation to other participant quotes, as well as providing context within which each idea emerged.

\section{$\underline{\text { 3.4 Population and Sampling Strategy }}$}

The sampling technique used for selection of the participants in this study was that of non-probability purposive sampling, targeting specific variables of interest, viz. gender (female); organisational rank (Senior positions: Supervisor, Superintendent and Managers); age and race (sampling was based on the racial profile of the company in order to explore issues across race, viz. Black, White and Indian). Purposive sampling enables the researcher to include specific variables of interest, free of the need to ensure the statistical inclusivity required in order to ensure generalisability (Terre Blanche \& Kelly, 2002). 


\subsubsection{Participants (Demographic Information)}

Table 2: Demographics

\begin{tabular}{|l|l|l|c|c|l|}
\hline Participant & \multicolumn{1}{|c|}{ Children } & Relationship Status & Age & $\begin{array}{c}\text { Length of } \\
\text { career }\end{array}$ & $\begin{array}{c}\text { Ethnic } \\
\text { background }\end{array}$ \\
\hline Ayanda & 2 children & $\begin{array}{l}\text { In a relationship (not } \\
\text { living together) }\end{array}$ & 33 & 8 years & Zulu \\
\hline Nosipho & 1 child (age 5) & Single & 27 & 4 years & $\begin{array}{l}\text { Zimbabwean } \\
\text { (Ndebele) }\end{array}$ \\
\hline Sindi & 3 children & Married & 33 & 10 years & Zulu \\
\hline Priya & 2 children & Married & 39 & 15 years & Indian \\
\hline Mbali & 1 child & Married & 34 & 10 years & Zulu \\
\hline Rene & 2 children & $\begin{array}{l}\text { Divorced, in a } \\
\text { relationship }\end{array}$ & 42 & 14 years & Afrikaans \\
\hline Kandice & None & Divorced, single & 35 & 15 years & Afrikaans \\
\hline Kim & None & Engaged & 29 & 5 years & English \\
\hline Nolwandle & None & In a relationship & 28 & 4 years & Xhosa \\
\hline
\end{tabular}

All women in this study were in leadership positions, Ayanda is a Supervisor and all other participants are Superintendents. The organisation has engaged in a systematic, companywide leadership program over the past three years; a key element of the program is to inspire all members in senior positions to consider themselves as 'leaders' in their own right. In particular, the methodology used in the leadership program is to develop 'transformational' leaders in the organisation. With Transformational leadership, the leader raises the aspirations of the followers so that their aspirations become fused. i.e. there is a mutual pursuit of a higher purpose (French, 1991; Bryman, 1996). As such, all members of the organisation are beginning to integrate the elements of 'transformational' leadership styles into their identity in the workplace. Women have 
subsequently begun to define themselves as 'leaders' and have taken on the responsibility of inspiring their teams towards the mission, vision, values and goals of the organisation. Therefore, the researcher deems it appropriate to classify all participants in this study as 'leaders' in light of the common social identity of transformational leadership that the organisational approach has adopted. Henceforth, participants will be referred to as 'leaders' as opposed to women 'in senior positions'.

\subsubsection{Position of the researcher}

My position in this research is as both an insider and an outsider (Westcott, 1979). In working within Company $\mathrm{X}$ as a Project Manager in an independent external consultancy firm, as well as growing up in the location in which Company $\mathrm{X}$ is situated, I have some prior understanding of the context which participants inhabit. As a woman, I have similar (and different) tensions, world views, and ambivalent experiences to other South African women. However, I am also an outsider as I have not experienced many of the life-circumstances that come with working in the mining field, being in a management position within a patriarchal environment where one is managed by and has to manage a group of male managers. I am also a 29 year old white psychology graduate, without knowledge of the technical field, nor the requirements involved in carrying out such roles. I am not married, nor do I have any children. Therefore, in representing narrations of women from various racial and ethnic groups, some of whom were mothers, wives, divorcees, etc., critical reflection of my own interpretations needed to be conducted throughout the interview. To assist in this process, I made use of social constructionist narrative approach to therapy outlined by Gerald Egan (2006). Firstly, "narratives 
is a powerful transformative element [of therapy] that enables clients to reinterpret, or re-author,

the events of their lives with new and different meanings and realities" (Egan, 2006, p.31). Secondly, active listening requires that the researcher applies elements of interpersonal communication, namely, attending (both verbal and non-verbal), listening, reflecting (content, thoughts and feelings), summarising and clarifying. Egan explains that active listening involves the quality of empathy that allows the participant to feel accepted and understood. By reflecting, summarising and clarifying my understanding of what the participant has said, I allow her to engage with me on a level which increases my understanding, and in-so-doing, clear up misunderstandings. Importantly also, this method allows participants to reflect back on their own narrative and reconstruct their stories.

\subsection{Data Collection and Procedure}

In line with the ethnographic approach, this study made use of in-depth semi-structured interviews as a method of data-collection. This method is structured by an interview schedule that directs the participants' discussion around specific issues and topics (Whitley, 2002). In depth, semi-structured interviews were conducted because this method is designed to detect, represent and elucidate the meanings associated with particular viewpoints from the individual actors themselves (Gubrium \& Sankar, 1994). Giving a voice to participants own representation of reality is important as it acknowledges their agency and gives them a greater sense of control over their lives (Rappaport, 1990). In this way, this method placed emphasis on understanding how the sample understood their experiences and the meanings they derived from their own 
experience. In particular, this method places value on the representations of reality narrated by the sample within their lived social context.

Individual interviews were conducted with female managers on site. Potential participants who met the sampling criteria were shortlisted by three senior Human Resources Managers of the organisation. A final selection was done by consensus in a meeting between the researcher and these three Managers. Out of the total of 10 female managers invited to participate in this study, only one participant was unable to attend due to work deadlines.

\subsection{Data Analysis}

Interviews were initiated, recorded, transcribed and examined through a set of systematic procedures (Strauss \& Corbin, 1990). These included research questions, field notes, participant responses, my experience in the interviews and my life experience. The analysis of the data was guided by the three main research questions viz. (1) How do women in mining narrate their experience? (2) How do women negotiate the tensions of a workplace that is both liberatory and limiting? (3) What are the implications of these tensions for women's wellbeing and personal, relational, community, and cultural identities? These broad research questions were used as a framework for the interview process.

Each interview was audiotaped digitally and transcribed by myself. The interview transcripts were read and coded for themes in relation to the research questions and the theoretical framework. Van Manen (1990) describes the process of conducting a thematic 
analysis. The first step involves transcription of the text into written form. This enables the researcher to explore associations that exist within thematic units that are identified and categorized. Parker (1999) describes a process of exploring associations within themes, labelled "free association". This process serves to strengthen the reliability of identifications and interpretations by taking into consideration different understandings that the text has for other people apart from the researcher.

There are various qualitative approaches available for analysing research data. The approach adopted in this study was a thematic analysis. Although thematic analysis is often construed as a realist/experiential method (Aronson, 1994; Roulston, 2001), Braun and Clark (2006) argue that it is actually compatible with both essentialist and constructionist paradigms. Holloway and Todres (2003) posit that thematic analysis should be seen, not as a specific method, but a tool applicable across different methods in that "thematising meanings is one of a few shared generic skills across qualitative analysis" (as cited in Braun \& Clark, 2006, p. 78). A thematic analysis conducted within a constructionist paradigm will differ in focus and outcome compared to essentialist/realist paradigms (Ibid, 2006). For instance, at the outset of a study an epistemological position is determined and guides what can be focused on within the data and how meaning is inferred. Braun \& Clark argue that a thematic analysis within a constructionist framework is appropriate in that one would pursue a theoretical interpretation of the sociocultural contexts, and structural conditions, that enable the individual accounts that are provided (Ibid, 2006). "Through its theoretical freedom, thematic analysis provides a flexible and useful research tool, which can potentially provide a rich and detailed, yet complex, account of data" (Braun \& Clark, 2006, p. 78). 
Further, Braun and Clark (2006) outline an array of advantages of a thematic approach, which positions this method as appropriate for Social constructionist research. Firstly, its flexibility allows for the use of multiple theoretical perspectives to examine the data, thereby offering a 'theoretically rich' description of the results. Thematic analysis is appropriate for studies, such as the present study, which involve participatory research with participants as collaborators. It enables one to summarise key features from a large data-set, thereby offering a 'thick description' of the data. Similarities and differences can be analysed and it can reveal unanticipated insights. It allows for social and psychological interpretations and can be useful in informing policy development.

Thematic analysis of the data was conducted in line with the procedure outlined by Van Manen (1990), which are as follows:

1. Read the text through several times, until a strong sense of what is being said is grasped.

2. Go through the text again, slowly, underlining or highlighting words, phrases or sentences, which are relevant to the research question.

3. Write these units (words, phrases, or sentences) out, assigning a number to each.

4. Give a name appropriate to the contents of each theme.

5. Look at the relationships between the themes. Do some themes contradict others? Does one theme lead to the next one? Can the story of the text be retold through discussing the themes?

6. Write a discussion in which the story is retold, using the themes to show how the research question has been answered through the data. 


\section{$\underline{3.7 \text { Ethical Considerations }}$}

Permission to conduct the study was granted by the Higher Degrees Committee of the Faculty of Humanities, Development and Social Sciences at the University of KwaZulu-Natal (UKZN) and ethical approval for the study was secured from the Ethics Committee of UKZN (Appendix B). Formal permission for the study and for access to the sample was obtained from the Managing Director of the sampled Mining Company, and a commitment was made to present the findings to the company, to inform the organisations transformation initiatives (Appendix D). In addition, informed consent was obtained from all interviewees (Appendix C).

At the outset of each interview, each participant was briefed on the aims and objectives of the study and was fully informed of her right to withdraw from the study at any stage if she so desired. As the research method made use of individual interviews, anonymity could not be guaranteed (Whitley, 2002). However, confidentiality was guaranteed to all participants and they were informed that although their responses may be used, their names would not be used in any and all reports emanating from the study, in order to protect their identity during and after the research process (Whitley, 2002). Participants were interviewed in their relevant workplaces; appointments were made and clearance was given by management for the employees to have time off from work in order to participate. Finally, the results of this study were reported back to study participants and to management, so as to enable the organisation to act on the findings and recommendations proposed. 


\section{CHAPTER 4 \\ RESULTS AND DISCUSSION}

\section{$\underline{4.1 \text { Introduction }}$}

The research findings are examined in relation to two central themes. The first theme, Navigating the interceptions between occupational identity and multiple identities, explores participants narratives in negotiating their identities at the points at which their multiple identities intercept, viz., Personal and Occupational identity interception; Motherhood and Occupational Identity Interception; Gendered identity and Occupational Identity; Ethnic identity and Occupational Identity. The latter theme, Negotiating a space for women in mining, explores participants narratives in challenging what they perceive as an 'invisible monster' in the workplace (interpreted as challenging hegemonic practices and norms); and analysing how women establish a collective identity, illustrated by their narratives that begin with 'we as women...'. Finally, this chapter concludes with a summary of the structure of the results.

\subsection{Navigating the interceptions between occupational identity and multiple identities}

The nature of identity that emerged from participant's narratives of the self can be viewed as an act of weaving together the multiple strands of the self, recognising the points at which these multiple strands intercept and where they diverge. So rather than merging these strands into a unified (and essentialist) self, participants seemed to recognise the fluid, dynamic and contextual sense of self and in-so-doing, participants began to, in their narrative, construct an authentic sense of self. For the purposes of this study, the analysis was focused on the interception between participants' multiple selves and their 'work-self'. 


\subsubsection{Navigating the intercepts of Personal and Occupational Identity}

A few participants reflected upon their 'non-traditional' childhood relationships as an anchor to their personal identity. In particular, three participants identified their relationships with their fathers, who introduced them to 'woodwork' or 'servicing the car', as being instrumental in the development of their traditionally 'masculine' as polarised from 'feminine' interests which are evident in their current occupational identity. As per Festinger's (1954) social comparisons theory, participants evaluate their own preferences in contrast to 'traditionally feminine norms':

Kim: ... when my father was servicing the car, he'd call me and I'd help him service the car, so I've always been taught that as a woman, you are still allowed in the garage, you don't have to go and sit in the kitchen...

Rene: My dad and I were always best friends and he taught me to weld when I was still in primary school, I did woodwork with him...I'm totally technical I am not an office lady... But at that time, before women were allowed in the mines, I had no option but to go into studying bookkeeping and all these normal things that women are supposed to do.

The above excerpts are an example of Foucault's (1980) notion of 'discursive resistance'. Rene and Kim emphatically reject the confinement of "normal things that women are supposed to do' such as "study bookkeeping" and "sitting in the kitchen". They do so by acting in ways which they perceive to be more congruent with their sense of self, viz., 'servicing the car' or 
'doing woodwork', and subsequently pursuing their interest in 'non-traditional' work, such as mining. This applies to all of the participants in this study, in that by entering the field of mining, they already reject pre-defined societal roles for women, specifically in the context of 'work'. However, as posited by Social Constructionist theory (e.g. White, 1991; Lax, 1994), this study revealed that the process of negotiating an authentic sense of self and resisting subjugated 'normative feminine roles' prescribed by society, involves more complex reflexive interaction across time and space, resulting in tension, ambiguity and the emergence of multiple subjectivities.

In contrast to discursive resistance, Foucault conceptualises 'disciplinary power' as a strategy whereby power is exercised within the minds of individuals (Hook, 2004). Disciplinary power is more pervasive and insidious than any other form of power as it is invisible and anonymous; and it becomes an internal process of 'surveillance' resulting in individuals disciplining themselves to embrace normative prescriptions in society (McHoul \& Grace, 1993). As stated by Foucault (1979), subjects "inscribe in themselves a power relation in which they are the principle of their own subjection" (p. 203). Steve Biko (cited in Alan \& Turner, 1986) captures Foucault's analysis of power by locating the potential for social transformation/or selfsubjugation within the subjectivity of individuals: "The most powerful weapon in the hands of the oppressor is the mind of the oppressed" (p. 73). With reference to the present study, Foucault's notion of disciplinary power and surveillance is demonstrated in participants struggle in transforming themselves from being 'soft' to acting and eventually becoming 'tough'. All participants in this study identified an inherently 'soft' element of their personal identity. However, when the 'soft' strain of the self intercepts the context of the workplace a direct 
conflict emerged. Participants perceived the workplace as a space which forces one to 'toughen up in order to survive in this industry (Priya)', because a 'soft person wouldn't make it' (Rene), would be 'ignored' (Kim); may be seen as a 'pushover' (Nosipho) or may be 'taken advantage of' (Ayanda). Participants perceive 'toughness' as a masculine trait that enhances success at work; by contrast participants perceive 'softness' as a feminine trait that hinders success at work.

From a Foucauldian (1980) perspective, participant's direct their gaze inwards and examine themselves in relation to what they perceive as 'effective' behaviour/traits within the context of work and discipline themselves to internalise what they perceive to be 'normative' behaviour/traits within a given context. For instance, Priya struggles to act in ways that 'others' (e.g. her husband) prescribe as normative behaviour for a mother and a wife:

Priya: My husband actually gets cross with me because I'm not that kind of mother you know .... if the child falls and gets a skinned knee... I don't run to him, pick him up... actually my engineering side kind kicks in first... it's quite bad...

Priya: My husband and I have actually been for an analysis... normally they have a profile for a man and a woman, a woman is a lot more emotional and I was on the other extreme. The psychologist said to me 'but you're even worse than some men', so I'm pretty bad with that, but what happens is I quickly evaluate how serious the situation is...

On the other hand, Priya illustrates her perception of appropriate behaviour in the workplace, and internalises this as a legitimate norm: 
Priya: You've got to develop a really thick skin because women by nature are a lot more sensitive and get offended a lot easier... Otherwise I wouldn't survive in this industry that's for sure. If you allow that to happen you'll be crying every day so you might as well just accept that's going to happen and toughen up. It doesn't help feeling sorry for yourself...

In order to initiate reflection on her identity, the researcher directs Priya to examine the stability of the 'engineering' sense of self across time. Priya then reflects upon the social contexts (childhood and the workplace), which served to mediate her identity across space and time. It appears that Priya is caught in an internal struggle in relation to how she was, how she is and how she should be:

Priya: [As a child] I wouldn't say a harsh thing to somebody, it wasn't in my nature to.... in fact it still isn't in my nature to speak harshly to people... Funnily enough, my nickname used to be bully, but I was a lot more sensitive. I always wanted to be a nice person... I was a bully because I'm the oldest sister and I have two brothers... I suppose from that kind of relationship I was always setting the boys in line....

One can recognise the shift in subjectivity occurring in Priya's narrative where she initially refers to her 'sensitive' nature in the past tense, she then moves to the present tense by identifying that 'in fact it still isn't in my nature to speak harshly'. She then locates 'others' perception of her childhood identity 'as a bully' but explains that this was a product of her role as an 'older sister'. Thus, Priya contextualises her identity, noting that she is inherently a sensitive person, but is able to adapt to accommodate normative 'ways of being' within each role. 
Similarly, on first impression, Kim came across as soft-spoken. During the interview, the researcher shared her first impression with Kim. Kim appeared to be physically taken aback by the researcher's perception, to which she responded:

Kim: I must say, I think most people would disagree with you. I'm quite hard headed, I don't do the screaming and shouting thing, I'm definitely not like that, but I generally stick to my guns if I know something is right, I won't back down easily...

Although Kim conceptualised herself within the normative masculine category of 'heardheaded', she illustrates that this element of herself emerged within the context of the workplace. She tracks the process in which she achieves a more 'assertive' sense of self:

Kim: I have had to change because I was a soft spoken person, but over the years I've learnt that I've got to open my mouth and speak my mind, otherwise I would be ignored. So that's definitely changed, but I wouldn't say for the worse, I'd say for the better because it's made me a more assertive person.

Kim narrates her typically 'masculine' interests and practices that differentiate her from normative prescriptions of femininity:

Kim: I'm not normal, I don't do my nails, I go get my hair done every now and again, but I don't have the same conversation topics as a lot of women. For instance when I went to the women's day function, it's difficult for me to talk to women, even here. A lot of them were secretaries and that type of line, so although they work for a mining company, they're still sitting and putting on the women roles. 
Kim also affirms her suitability for the mining environment by emphasising her technical and physical competencies against stereotypical images of women:

Kim: Women are less technically minded... more into arts and crafts and cooking which might be part of the family thing and so when I say I go home to break down a wall, a lot of people just don't get me, why on earth would you want to do that, I might damage my gel nails or something...

Kim's construction of herself as different from the 'other' challenges the notion that all women are physically too weak, not technically minded, or not interested in 'dirty, mine work'. Ironically however, Kim deconstructs the feminine stereotype as it applies to herself by reifying stereotypes about women in general, exemplifying the 'while other women are like that, I'm not like other women' notion of identity. This result is consistent with Social Identity theory, and Ely's (1995) finding that women in male dominant industries tend to "exaggerate psychological and behavioural differences between men and women in a manner that is consistent with sex-role stereotypes; evaluate feminine attributes less favourably in relation to the organisations requirements for success; and describe themselves as more similar to men and less similar to women on psychological and behavioural dimensions, and therefore still rate themselves in line with meeting the organisations requirements for success" (p. 596). Kim's relational orientation, as defined by Joireman (1997), fits into the traditionally masculine individualist style in that while Kim asserts power in challenging current gendered norms, she does so from an individualist standpoint. It is important to note that in future training initiatives, women may achieve greater agency if they were to adopt the prosocial orientation, where they reflect upon 
their own narratives and question the accuracy thereof. The 'truth' status ingrained in Kim's narratives about the stereotypical traits of women illustrates the powerful effect that liberalhumanist and essentialist notions of identity has on society. Creating a space for women to question these normative prescriptions of gender may serve to 'free' women who may be confined to such roles (Lewis-Williams, 2001). In light of Foucault's argument regarding the micro-physics of power, women who are actively involved in questioning the validity of stereotypical notions of the feminine self take agency in deconstructing such notions, thus limiting the extent to which such images are perpetuated in society (Hook, 2004).

While Kim and Priya identify the 'tough' thread of the self as intercepting all spheres of their lives, other participants narrate the interception of their 'soft' sense of self into the work context as a somewhat painful experience. In a sense, it seems that the pressure to internalise prescriptively 'masculine' behaviours may, in Foucauldian terms, be a violation in the sense that their freedom to 'act' in ways that are congruent to their own narrative is being restricted (Hooks, 1989). The participants' narratives illustrate their perception of how they should behave within their roles at work, how they would prefer to behave, and their struggle against the disciplinary power of such normative prescriptions in the workplace:

Nosipho: Before I thought, I love laughing, I love seeing the person in every situation, but recently I have learnt I can't walk around laughing, sometimes I just need to walk around with a stern face, because if you are a woman, the men at work think "yes she is a pushover".. 
Ayanda: I told myself that now I'm in that male dominated area so now sometimes I have to behave like one, behave like them just so they don't take advantage of me...

Rene: Some days I did cry in the beginning but no one knew it... You need to have a strong personality to be able to put up with all the negativities in the beginning and turning it around I don't think a soft laid back person would make it here. From the way I was treated over the past 15 years, I think I fit in better with men than I do with women. I've got a very soft side when I'm out of Compamy X but at work, I act just like they do.

Sindi: [The mining environment] hasn't changed the way I am because I wouldn't be comfortable not being myself, that's my problem, I still want to be the same person, I don't want to be changed just to make sure that I fit into a certain group. I don't know how to be tough and I don't want to learn how to be tough because that's not me...

Despite Sindi's resistance to the practice of being 'tough, she, along with the majority of participants not only internalise and conform to traditional masculine behaviours expected within the mining industry, they become actively involved in these practices. This can be likened to West \& Zimmerman's (1987) conception of 'doing gender'. From a social constructionist perspective, participants narratives of 'doing gender', illustrate the reflexive processes of practicing normative conceptions of appropriate 'masculine' behaviours, such as 'being tough', 'putting on a stern face', and 'acting like them'. The extent to which these practices become integrated within participant's identity differs for each person. For example, as evident in the excerpts above, although participants may 'act' tough in the workplace, they are able to exercise 
their 'freedom' from normative behaviour in other contexts. For instance, Rene says "I have a very soft side when I'm out of Company X', Ayanda accounts for the emergence of a 'tough' identity as 'because I am in that male dominated area I sometimes have to act like them'. This introduces the notion of a multiple sense of self, and multiple identities.

The researcher interprets participants struggle to conform to 'masculine' prescriptions of normative behaviour in the workplace, against their own salient sense of self, as an illustration of disciplinary power that ultimately serves to perpetuate the status quo. The 'ideal' self in the work context is described by participants as 'being tough', 'harsh', 'have a strong personality' and 'to supress the soft, sensitive and emotional side of the self'. According to participants, such demonstrations of what they perceive to be typical feminine traits are counterproductive in the work environment. For example, as illustrated previously, Priya states: "You've got to develop a really thick skin because women by nature are a lot more sensitive and get offended a lot easier... Otherwise I wouldn't survive in this industry that's for sure”. Participants discipline themselves to portray their perception of being 'tough' and 'act like them [men]' in order to 'survive' in the industry, and assert their authority effectively, so as to avoid being 'ignored' or being seen as a 'pushover'. In so doing, participant's give credence to the perception that women are not suitable for leadership positions, because they are too 'soft', 'emotional' or 'sensitive'. Such a perception perpetuates inequality and creates an invisible barrier preventing women from progressing (Lahiri-Dutt \& Macintyre, 2006). In Foucauldian (1980) terms, participant's narratives in this regard suggest that women discipline themselves to embody 'masculinity'. Behaviours which they deem appropriate for the work-context are inscribed onto women's 
bodies through their socialisation in and corresponding engagement with prevailing historical and cultural notions of 'masculine' or 'patriarchal' workplace behaviours.

The internalisation of an ideology that positions women as 'soft' and thus ineffective leaders serves to reify hegemonic masculinity. Ayaman and Korabik (2010) highlight that men are traditionally afforded higher social status within society, and particularly in the mining industry, which provides them with greater access to power, resources and privilege than women (Ibid, 2010). Thus, gender is both "a hierarchical structure of opportunity and oppression as well as an affective structure of identity and cohesion" (Ferree, 1995, p. 125). The "higher social status' within society can be interpreted as a function of power, whereby oppressive forces operate within a net-like structure, where both men and women generate and sustain discourses of 'truth'; a 'truth' that ultimately benefits those in dominant positions in society (Foucault, 1980). The new leadership paradigm, such as the transformational leadership paradigm (French 1991; Bryman, 1996; Ayaman and Korabrik, 2010) may serve as a counter-discourse for women to embrace in resisting the normative autocratic prescriptions of an 'effective leader'. The transformational leadership approach encourages leaders to utilise a more androgynous leadership style, which may authenticate women's own preferences in engaging with their teams (Ayaman \& Korabik, 2010). Further, such an approach may increase 'leadership effectiveness' across the organisation (French 1991; Bryman, 1996). 


\subsubsection{Intercepting 'motherhood' in the workplace}

Participants in this study were conflicted when considering the interception between their work-self and their self as a mother. Participants with children reflected upon the emergence of their motherly traits in the context of their role at work. However, at this interception, participants seemed to experience a conflict in the extent to which they unveil this 'nurturing' quality. Participants narrate this conflict in terms of creating a balance between nurturing and directing, in order to avoid distancing themselves from their team. As such they position their identity as a 'mother' in ways that are more congruent with the patriarchal construction of leadership. For example, Nosipho initially positions her role as a mother and her role in the work-place as two distinct 'personalities', however upon reflection, she recognises the overlap. It would seem that Nosipho perceives herself as a 'mother' as incompatible with her effectiveness as a leader:

Nosipho: I have two distinct personalities; one for work and one at home... Okay at work, I am in charge of my team's safety, so there is a different personality. At home they almost... they're not too distant but somehow there is an overlap that they cross over into each other, because at home I am the mother, I am the giver, at work there is some nurturing but it is on a stricter level..."

Leigh: And how do you think your team perceives you:

Nosipho: They think I am this mamma who is going to make everything better for them because they keep calling me Mama. Which is not a bad thing because most kids trust their mothers, and if I am seen as a mom it means the same thing I will discipline you... but the first week was difficult, and it is also the perception of a 'mama', "she is another 
woman who is just going to be floating around" but I am here, I am hands on, I am part of the team...

As evidenced above, Nosipho draws upon the disciplinary element of herself as a 'mother' as more compatible with her role as a leader. Similarly, Ayanda perceives a need to supress the extent to which she unveils her 'nurturing' side as a mother in order to prevent being seen as 'failing to lead' or 'weak'. Ayanda's perception illustrates the insidious strength of disciplinary power, which she exerts upon herself in order to limit her freedom to behave in ways which may be perceived as weak. In so-doing, she constructs a leadership approach which combines maternalistic and masculine styles of influence:

Ayanda: being a supervisor is like being a mother sometimes;even if you need to discipline them, you must not shout at them but tell them as you would explain to your kids what you want and how you want it. But then there will always be those maybes... maybe they will see that she is failing to lead us, you must not allow them to see that, they must see you as someone who is strong and capable to lead them... you must bring that feminine side of you like you are guiding them as a mother but you also need to apply that masculine...

Similarly, Rene recognises her leadership style as congruent with her style as a mother. However, Rene acknowledges, previously, that she has to limit the extent to which she reveals her 'soft side' in the workplace. Rene positions herself as a mother, thereby subordinating her team to a 'child-like' status: 
Rene: "I think being a mom and raising and being responsible for my kids I actually sometimes do that to my guys, I treat them like my family and I would look after them and protect them at all costs. My guys will come straight to me with a problem, even though it's not work related.

The ambiguity illustrated by participants' narratives presented above, in their need to become 'tough' but at the same time inhabit a more 'motherly' and 'supportive' leadership style, reflects the shifting ideological terrain within Company X. For instance, although Company $\mathrm{X}$ is moving towards a more Transformational organisation, hegemonic masculine management approaches (directive, authoritarian) are still given credence in this environment, therefore there is a power-dynamic at play between democratic versus autocratic value systems. This places women [and men] in leadership positions in a conflicted role, caught between the dichotomies of being too masculine or too feminine. Smart (1985) captures the tension women experience in negotiating between 'masculine' and 'feminine' notions of themselves, in terms of a power dynamic: "The basis and permanent condition of existence of power is to be found in its perpetual relationship of provocation and struggle with freedom... Every relationship of power implies a potential strategy of struggle" (p134).

Some empirical studies show that women are generally more egalitarian and nurturing in their leadership style than men (e.g. Fine, 2007; Daft, 2005; Tamerius, 2005). In relation to the present study however, the extents to which women feel that they are able to exercise such characteristics are strained by hegemonic norms. This creates conflict for women and 'negative freedom' (Lewis-Williams, 2001) in exercising agency in embracing an authentic leadership 
style. It seems that a tension exists between brining positive nurturing qualities to the workplace authentically against using traditional 'feminine' qualities such as nurturance and motherly discipline in disingenuous ways. Thus, what may be perceived by participant's as egalitarian, nurturing and transformational leadership qualities is actually a form of subtle authoritarianism which flies in the face of transformational leadership. It seems that participants stand at the intersection of this tension, and are not aware of it. Grimshaw (1986) argues this point along similar lines, "Using mothering as a model of connection with others, particularly in an organizational setting, merely replaces one form of superiority and elitism (paternalism) with another (maternalism). The mother-child relationship is not an egalitarian relationship, since the mother is more knowledgeable or competent than the child, and responsibility is not mutual, since the mother is responsible for the child's welfare, but the child is not responsible for the mother's welfare (Grimshaw, 1986, pp. 250-251).

\subsubsection{The construction of a gendered work identity}

In their journey towards constructing and locating an authentic sense of self, participants' reject certain polarised and 'hegemonic masculine' traits in favour of more positive 'traditionally feminine' traits in the work place context. This seems to create ambivalence within their own narratives that leaves them straddling two contradictory identities. Participants thereby construct a gendered workplace identity for themselves by linking their interests, behaviours and psychological characteristics to their internalised notions of masculinity and femininity that are usually prescribed by society (Haiden, 2002). In contrast to the previous section outlined above, where women begin to incorporate 'masculine' traits into their roles (to different extents), the 
following excerpts demonstrate how women begin to distance themselves from their notions of 'masculinity' in order to emphasise gendered differences, and in particular, aspects of 'femininity' that they embrace. In essence, women position and construct themselves as the 'other' by reifying hegemonic masculinity:

Kim: I can't say I've become like them [men at work] because I've noticed a lot of men, not all, but a lot of them like to [take a position of] "it's my way, even if I'm wrong, it's still my way". I haven't taken it that far, I must be honest, other than that, I keep with who I am and I make it perfectly clear that I'm still female. Like for my birthday, I generally bake something and bring it and say, look, see I can do something, I can bake.

Note the contradiction in Kim's narrative above, where she now positions herself as someone who can 'bake'; whereas previously she defines 'women who are at home cooking' as polar opposite to her. However, in asserting her superiority to her perception of hegemonic masculinity, she reifies the stereotypical feminine traits by applying them to herself.

Throughout their narratives, women position themselves in gendered ways, at some points polarising their 'feminine' and 'masculine' identities:

Rene: Caring... that's a quality that a male does not have in a supervisory position. They're not used to it I suppose. I've had comments a couple of times that I'm very protective of my people... I've just got that motherly touch. 
Ayanda: I see there's no sympathy from him like with us women we know how it goes, we are caring... with the men they won't care, all they want is for the job to be done.

Mbali: A man has got an ego, he has got his pride to protect. I have got my pride as well, it is not like I don't have my pride, but then I feel that there are some things which I need to hear so that I can build myself and become a better person...

Priya: When men speak to each other I feel like they kind of miss each other and it becomes a power struggle whereas when a woman asks for something she asks it with a lot less authority and a lot more requesting and it generally works better.

The excerpts above vindicate Talbot and Quayle's (2010) argument that, not only men but women too, are active agents in the production and maintenance of masculinities and emphasised femininity. Ayaman and Korabik (2010) suggest that examining more androgenous notions of leadership may facilitate the process of eradicating the masculine stereotypical image of a leader, eliminating the ethnocentrism that creates ingroup- outgroup biases, and equalizing access to power and privilege.

\subsubsection{The deconstruction of ethnic identity in the workplace}

An important theme which emerged amongst the black participants was the additional responsibility for extended family. This may serve to amplify stress levels for African women in the context of multiple stress factors in the development of their families and careers. However, 
for participants from this study, this did not appear to be the case. Numerous factors assist these women in coping: Firstly, many women received support from their extended family members in looking after their children while they focussed on their careers; secondly, these participants belong to an informal support group for women at Company $\mathrm{X}$, thirdly, these women feel a sense of achievement and fulfilment in giving back to their families [and extended families].

Sindi: The way I grew up, I must say, I got the best opportunities compared to my siblings... I was the only one who was able to study at that time and then I was the first one to get a decent job... and then I was able to do something about them. Like I was able to send my younger brothers to school and now they're qualified and so it's just doing good with what you have and be grateful at all times... That helps a lot in terms of putting everything into perspective because really you can't always be running after what you don't have.

Contrary to the notion of caring for the extended family as a source of stress and burden, it is apparent from the above quote that Sindi has constructed this experience into a source of personal affirmation that validates her purpose in proscocial rather than individualistic terms. She is drawing succour from the cultural macro-politic. In relation to the net-like structure of micro-macro physics of power that Foucault (1980) speaks to, Nosipho's narrative may illustrate one of the coping strategies that those from marginalised echelons of society adopt. For instance, by constructing her role in her extended family as a provider, regardless of gender, marginalised groups defeat the oppressive force operating within the macro-physics of society (e.g. socioeconomic sphere), by liberating each other at a 'collectivist' and prosocial (Joireman,1997) 
micro-physical sphere. At this interception, Nosipho resists this oppressive force and acts in a way that not only liberates herself, but also her family.

Another common theme was the tension participants experienced at the interception of their normative role within the community and their role within the workplace. At this intercept, participants question their own 'collective' identities and begin to doubt the efficacy of their own identities. This result exemplifies Bradley and Healy's (2008) argument that multiple identity affiliations (e.g. leadership identity and cultural or ethnic identity) may create ambiguity about who 'we' are and who 'they' are, leading women to question the salience of gender as a mobilizing identity. The excerpts below illustrate participants' engagement in multiple identities, in some instances, participants reflect upon their agency in locating themselves within the context of diversity, whereas in other cases, participants seem conflicted in the saliency of their own collective identities.

Nosipho reflects upon her 'non-traditional' relationships with her parents which have impacted upon her ability to challenge traditional cultural relationships. For example:

Nosipho: I grew up in a non-traditional family... everyone is open and we would engage each other, I would challenge my dad but he allowed it in a controlled and structured way, my parents discussed things as equals... Now working in this environment I find that it is easier for me for example, to tell this 55-year-old man to stop what he is doing if it is unsafe... I can challenge him. So the way I have been brought up it actually helps a lot. 
Later, Nosipho provides an example of how she resolved a generational conflict with a 'subordinate' in the workplace. Outside of the workplace, Nosipho would usually refer to elder men as 'baba' (father), however, based on structural norms within the workplace, she deems this behaviour within the workplace as inappropriate:

Nosipho: I am a young black woman and I am in charge of men who can be very traditional... someone said I must call him dad or father because his child is my age.

I said no, at Company $X$ we call each other by our first name, so I can call you by your surname, not your first name, but I will not call you father. Because then it blurs all the work lines.

This type of generational conflict was prevalent amongst all black women in this study, and all participants react in a similar way to Nosipho, e.g.:

Mbali: There are five of them, they are baba [Mbuyas]. And I explained the work ethic to Thomas: "you know, in terms of work ethics I am not supposed to be calling you baba. I am supposed to be calling you by name." I even said to him, to explain, look at your payslip, they don't write baba on your payslip because you are over 50, they write there Thomas that is it. So I explained this to him...

Given the type of relationship Nosipho had with her father, Nosipho feels confident in resolving a generational conflict, however when faced with what she perceives as gendered practices within Zulu culture, she feels that she has no choice but to conform. Given the emotional significance Nosipho places on gender equality, such practices conflict with her identity as a leader: 
Nosipho: I had to manage a team of culturally traditional men, in the meeting they told me "you can't stand because you are a woman and you must not look at men in the eyes" And they gave me this intimidating look so eventually I sat down... I can't put my eyes anywhere. It just it takes away your confidence. It takes away your standing. It takes away the way they respond to you afterwards, if you can't recover from that.... You could either thank them for telling you and hear what they are trying to say, or you can be intimidated...

Further, Nosipho relates that it is more difficult for her as an African woman to establish her leadership identity amongst Zulu men than it is for white women:

Nosipho: ...because I am African and I know African people... but I have a colleague, she is white... and she is not going through what I'm going through, because she is oblivious to the cultural aspect of these things.

Rene and Kim confirm Nosipho's perception; in their experience they have little problem relating to Zulu men, provided they prove their competence. Rene describes how she displayed acceptance and respect for traditional cultural practices while at the same time, she put effort into earning their respect by displaying her technical ability and capacity to lead:

Rene: ...it's very difficult for a white lady to actually earn the trust of traditional Zulu men from the older generation. They will kick against it like crazy until you prove to them... I had a very senior traditional Zulu leader, actually one of the tribal leaders, he used to just ignore me... then one day I went across to him and I told him 'I respect that you as at that level, that you are the senior and these guys listen to you because you are 
their leader'. I said 'but here I will respect you as a senior as long as you respect me' and then he turned around, he was my best guy....

Kim experiences a similar tension to Nosipho. Nosipho is black, but Zimbabwean, and relates the tension she experiences with Zulu men. Because she is African, she experiences pressure to conform to traditional Zulu cultural practices. Kim on the other hand is white, she experiences little difficulty in relating to Zulu men, provided she proves her competence. Kim, as an English white woman, specifically mentions her conflict with white Afrikaans men:

Kim: Most of the Zulu men have been quite accepting of me, but there have been some that have been quite staunch in the view as well, "you're a woman and a woman's role is down there and I'm up here", so I have come across that some times, but actually, to my shock most of the Zulu men are a lot more accepting. I think the biggest problem is the Afrikaans men that were generally a lot more difficult to get through to, they were quite a big challenge. I would ask the Afrikaans guy to do something for me, it was like pulling hens teeth...

It is important to note that although these conflicts are intra-racial, they are still ethnic conflicts. Zulu men, according to Kim, Rene and Nosipho, are far more accepting of white women then they are of black women who fail to adhere to their cultural practices. However, according to Kim, she experiences a stronger resistance in exerting her authority from Afrikaans men. Greater pressure to conform when perceived as part of the in-group. These women are faced with the burden of negotiating the pressure of in-group conformity in addition to broader 
categories previously outlined. These findings indicate a need for future research which explores gendered intra-group and intra-racial conflict in the mining sector.

For Sindi, she struggles to conform to Eurocentric organisational practices. In the quote below, Nosipho narrates the internal struggle she faces in challenging her Afrocentric practices in order to align herself with eurocentric practices. Unlike Nosipho, Sindi's identity is historically rooted in such practices. In essence, Sindi is unconsciously involved in the acculturation process:

Sindi: I tried to improve myself because that was also one of the issues where in our culture, you're not supposed to look people in the eye and so I don't look at people in the eye. I tried to improve myself, I don't want to do it and it's difficult to get out of that stigma but since I'm aware of it and now I am aware of how it affected my performance at work, how people perceive you, it's like they think you're arrogant if you don't look at them when you talk. I have been on all the training to try and improve myself but ja, I'm actually a very shy person, even my mother knows that, I don't talk much and I'm just quiet...

Sindi's effort to embrace normative behavioural practices in the workplace is evidenced by her desire to adopt such behaviours in her role as a mother and a wife at home, despite the difficulty she experiences in 'achieving' this transformation:

Sindi: What I'm trying to do now is... the same principles that I apply at work, to apply them at home, but it's not easy because at work, you're so patient, you don't just shout at 
your team...if I can take that home maybe I can have a happier home life, but it's not easy.

Sindi and Nosipho's conflict illustrated above can be interpreted as an internal struggle to preserve their identities, while at the same time engage with diverse groups and enact behaviours that are considered appropriate within various contexts. Swann and Bosson (2006) capture this struggle in their postulation that "the survival of people's identities rests not only in their own hands but in the hands of others" (p. 1).

Although Sindi's conflict is applicable across gender, women may experience this conflict differently to men, especially because they are not only pressurised to conform to dominant cultural norms, but also 'masculine' norms; they are not only women, but African/White women -which creates a sense of double-oppression. More research in this area is vital, along with diversity training to enable women to embrace their cultural identity in ways that liberate them. In this regard, diversity training programs that promote Universalist and essentialist notions of being should be eschewed.

In summary, ethnic conflict was perceived as greater within groups and more facilitating across groups. The common factor that women seem to perceive as critical in managing people is the ability to prove one's competence. Women's narratives seem to reflect Eagly and Karau's (2002) position which characterises the leadership challenges that women confront as a maze consisting of many barriers that they must negotiate. According to Ayman \& Korabik (2010), such challenges can have an important impact on many aspects of leadership, particularly when 
there are factors that privilege those in 'dominant positions'. In order to achieve success in the workplace, women are pressured to succumb to the hegemonic workplace ideology. Ayman \& Korabik (2010) suggest an alternate way for women to progress within such contexts: "If leaders are to be effective in a diverse society, they need to understand their own preferred style and behaviours and how these may differ from those preferred by others. Otherwise, their interactions with others are likely to be fraught with misattributions, misunderstandings, and misinterpretations" (p. 157). Within the South African context Van Binsbergen (2001) argue that the Ubuntu world-view or guiding philosophy may assist in overcoming the types of contradictions inherent in participant's narratives, by providing a 'collectivist' space that may alleviate tensions and hostilities in the organisation. Mbigi (1997) concurs: "Ubuntu will show a way to work together and will create a rainbow mentality in our organizations characterized by a high degree of cultural, racial, religious, tribal, and political tolerance” (p. 8). Moreover, Ayaman and Korabik (2010) postulate that by increasing the cultural awareness of leaders about different norms of conduct, leaders may enhance the level of trust in their relationships with their subordinates. An examination of the effects of gender and culture has the potential to change our definition of what constitutes leadership and what is considered to be effective leadership (Ayaman and Korabik, 2010).

\subsubsection{Keeping all my diamonds intact}

All participants recognise the challenge they face in creating an optimal work-life balance for themselves. Priya uses symbolic imagery in capturing this challenge, which seems to be generic for all participants depending on the types of roles they perceive as salient in their lives. 
Priya's conceptualisation of work-life balance provides a superlative representation of the challenge that women with multiple roles face:

Priya: it's a balancing act so whatever I've chosen to hold as my diamonds I've got to make sure that all of them are intact without affecting the other one... For me those diamonds ... okay my career is important because I do want to earn this income and to be able to fulfil some kind of a function where I feel I'm needed. My family is the other, obviously my marriage and then my children and they must be happy in their jobs and whatever it is they do. So my husband can't always be sacrificing his work for mine and I can't always be sacrificing my work for his because his work is also important to me and how the kids do in school is also important to me.

In 'balancing her diamonds' Priya chose to be inflexible in her career (i.e. not working late hours) in order to be available for her children. As such, Priya describes the impact on her career development of not conforming to the 'ideal worker' norm. Priya conceptualises this as a choice, despite the limitation in alternative options available to her:

Priya: It feels like for fifteen years I haven't really grown in my career, if you compare me to a guy for example you know. I decided that my family would come first, that was my decision and I don't regret it I'm glad that I did it that way instead of sacrificing their happiness for my goals and it wouldn't have been worth it. So no it was a decision that I made...

Similarly, Rene describes the way in which she obtained a balance between work and raising her children. Being divorced, without financial support, or support from her family (as 
both her parents had since passed away), Rene may be perceived as having less space to negotiate a balance between work and her family than other participants. However, her narrative illustrates her resilience in balancing both roles, and demonstrates how she identifies her work role as enhancing her relationship with her children:

Rene: I've learnt to do a complete balance, my work is still my work and my child is close, I try my utmost to keep them close to each other but obviously if something happens to my child I will definitely attend to him first... My kids are very independent, they had to learn to be independent with me working late, not always coming home. They had to learn to live without me, you know I had someone to take care of them. I juggled it quite well and I think both of my boys have got the same values which is good, I try to be an example like my dad was to me.

Rene notes that in her effort to 'balance her diamonds' (children and career), she had to sacrifice pursuing a romantic relationship:

It's a self-sacrifice you do make but, a lot of people have asked me why I never got married again so I said because I've raised my kids, that was my priority in my life, I did not have time to go and find a husband....

Participants without children were apprehensive about the extent to which their career may be hindered by having a family. For example, Kim reflects upon her perception of 'climbing the corporate ladder' in terms of discourse on the 'ideal worker', and the perceived restriction this may place on women with children: 
Kim: You're going to have to be willing to go the extra mile. Most women have children and extra responsibilities outside work and sometimes your job is going to require you to either work shifts or work unplanned overtime and that's where you've got to be willing to put in the extra bit and not say, listen it's time for me to go now, I've got to get back. I know it makes it difficult, but that's the lengths you've got to go to be successful, especially as a woman because we've got those responsibilities.

In addition to Rene, two other participants view their jobs as having a positive effect on their children in terms of their independence:

Sindi: I never spent time with my first born because I got him when I was still studying. But he's so mature that I don't even feel that bad that I wasn't around, he understands the way things had to happen and I'm so grateful to have a son like him... but I provided for him at least, it's a choice between that...

Mbali: [Back then] They gave me the job, and then the worst thing that he could have said, he told me that I am going to be working shifts. But because I was hungry, I said that I will do anything, but I know as a mother [and as a wife now] I can't do this standby thing for the rest of my life, it is just a stepping stone but it's going to take me long to move up...

One of the participants, Kandice, who is divorced and without children, emphasises her choice in focussing on her career and other areas, rather than pursuing a relationship: 
Kandice: I got divorced about five years ago, so at the moment I'm single, I am very happily divorced and to be honest with the amount of hours that I am working, I think that even if I was still married I would have been divorced now. Even my friends at one stage said I'listen we never see you anymore you are always just at work'...

Participants also emphasised their career as a mode of self-fulfilment and a means of gaining independence. Two participants, Mbali and Rene, emphasised their preference for their role in their careers to the role of 'submissive wife' or 'house-wife'. These factors may serve to reduce dissonance for participants who made the choice to pursue their careers over occupying traditional feminine roles in society:

Nosipho: managing and getting to a point where I can do my own thing, pay my own bills, means that I can stand up on my own two feet and not be out there knocking on someone else's door asking to borrow money

Rene: ... when we got divorced all of a sudden I had to find my own place, my own money, my own vehicle, all by myself. It made me stronger, but not in a negative way. I don't sit back and let people walk over me like I used to, always being the submissive wife, now I'm not like that.

In keeping with the literature, participants viewed their work as central to their lives, a means to attain self-fulfilment and fulfilment of their economic needs (Haworth \& Lewis, 2005; Koekemoer \& Mostert, 2010). One participant notes that when she had children, she was not willing to work extra hours at the expense of her children, and thus, she feels that her career 
development remained static for 15 years. However, this participant constructs this 'sacrifice' in liberatory terms: '...now I am more in touch with the guys at the bottom'. Single mothers were faced with the pressure of spending more time at work in order to provide for their children. Two participants spoke of having to sacrifice their pursuit of romantic relationships for the sake of their career. However, despite these sacrifices, all participants emphasised their decisions as a choice and that they have no regrets. Mothers preferred to work rather than be dependent on their families/husbands. Two participants expressed that their career role enhanced their relationship with their children. However, it may be that such participants perceive the positive effect of work on their children's lives as a means of challenging the dominant ideology, as per Hook's (2002) argument, that working women may be seen as providing less quality care for their children.

Participants narratives illustrate several juxtapositions in their choices, (e.g. being seen as an uncaring mother, or not progressing at work; being unable to provide for their children or being seen as an 'absent' mother; facing the stigma of being a 'bad mother' or 'bad wife'). This is the terrain in challenging hegemonic or dominant ideological positions, e.g. Hook (2002). However, there is a silence in participant's narratives regarding challenging the role of their husbands/partners to develop more egalitarian relationships. Participants take on the role of 'carer' in an uncontested way in their narratives. For instance, Mbali states:

Mbali: When I had to go for shift-work, my husband actually understood, he said to me, it is up to you, you wanted this career, you told me that you don't want to be a housewife, so I am giving you the chance 
Participants' narratives on 'motherhood' and 'caring' which they assume in uncontested ways illustrates the power of hegemonic discourse in prescribing gender biased division of "carework' (Morrell \& Jewkes, 2011; Kruger, 2006). The silence in participants' narratives in this regard may illustrate that participants assume an inequitable position as carer, without being aware of their agency in the extent to which they engage in their various roles. The excerpts above exemplify the insidious nature of micro-political power; participants own subjective engagement in it and the subsequent reification of polarised masculine and feminine norms (Foucault, 1980). However, despite participants' silence in their subjection to prescribed roles, the extent to which women accept or challenge these gendered roles requires further exploration. An intervention that reinforces prosocial values and behaviours (Joiermen, 1994) and that includes men, is recommended to deconstruct hegemonic ideology and subsequently free both men and women from their own hegemony (Lund 2006; Morrell \& Jewkes, 2011; Madhavan et al, 2008).

\subsection{Negotiating a space for women in mining}

\subsubsection{Challenging the 'invisible monster'}

Many participants described the 'biggest mistake' they made at the start of their career in mining was "allowing men to help" them. In conventional society, women often allow men to assist them with 'jobs' that are considered 'men's work', doing the 'dirty work' or carrying heavy items (Lahiri-Dutt \& Macintyre, 2006). Participants in the present study view this behaviour [allowing men to help them] as reinforcing men's dominant position in society by allowing men to view women as 'incapable' of doing this 'dirty work'. Participants narrate that 
they "quickly realised that allowing men to help them would result in [them] losing all credibility". Sindi describes her first experience in this regard:

Sindi: When I started here, no one wanted to give me any work, they would actually take work away from me... One day I was suddenly transferred to a different section... I found out later that I was moved away because a few of the guys were saying I didn't do anything. I know I am not 100\% right, I should have.... that's why even if a person is trying to be extra special and trying to carry stuff for me... I did show that I can do things by myself, I don't need any special treatment. I don't want people to feel pity for me and think because I'm female I can't do this and if I need help I can ask for it!

This experience was shared amongst most participants. Participants who had not experienced this for themselves expressed knowledge of the potential pitfalls of letting men assist them. Nolwandle explains this type of scenario as an insidious "invisible monster" due to the lack of transparency around decisions to privilege men over women. She asserts that this is equivalent to psychological abuse:

Nolwandle: "the victimisation it is very subtle, you will not see it. It is not in your face, like other mining companies it is in your face... It is subtle... seriously, you can't even raise your voice about it because they will be like, what are you talking about?..., it is psychological, like when you are in a relationship and you are getting abused psychologically, you don't have any scars to show for it. You just know that there is a general feeling of... we don't really want you here, but it is not visible. I don't know how to explain it...." "...everybody is pretending as if they are happy, and then suddenly an email comes, we are not happy not because... she is just useless you know. I don't even 
understand, there is nothing specific... that is a way of killing somebody's spirit...." "So it is like there is a monster out there but there is no monster."

Kim relates how, by insisting on her own independence, it creates a more positive perception for future generations of women in mining:

Kim: It's one of the biggest topics that comes up... you get some guys who do this... but I won't allow it... I try not to give that impression because I don't want it to come back later, "these women, they can never do anything for themselves" and I don't want to create that perception for women who might be filling my position later on...

Ayanda links the general perception that women at the mine hold about men "look at those women coming to take our places now" and the experiences of women at the mine "they were holding information from us, and not allowing us to do things for ourselves" to the reaction women take in challenging these perceptions:

Ayanda: ... they talked behind our backs that we wouldn't make it because we were women, but we did show them that we can do it".

One of the most frequent terms used by all participants in their narratives, was the word "prove". Participants conceive that throughout their experience within their careers, they are considered inept by default, and in order to achieve any form of respect, acknowledgement, career progression or success there is a constant prerequisite for women to prove themselves: 
Nolwandle: As a woman, you know they say you need to work 10 times harder because you need to convince, you need to convince. You really need to convince. You wouldn't get away with just being okay... You need to convince.

Sindi: ...no matter how hard you try they will stick with that stigma, you need to be working extra hard to just try and be normal... if you are a male you have already achieved, you don't need to prove anything ...

Rene: I had to prove to them, listen I am not just a little lady walking in here... you can switch the males mind by showing them technically that you can actually do something better than they can...

Ayanda explains the huge impact of making mistakes as a woman, as it serves to reinforce the negative stereotype. She feels as though her competence is her only tool to carve a space for herself in her career:

Ayanda: you do it to your best of your abilities and making sure that at all times no one can find fault with how you do things because that's the only thing you've got...

It would appear that the narratives above illustrate an effort by participant's to challenge existing gendered discourse within the workplace. This discourse seems to subordinate women (e.g. "we have to work 10 times harder just to be normal"..."you need to be working extra hard to just try and be normal; I don't want people to feel pity for me because I'm female") while reinforcing men's dominant position within the ranks of the organisation (if you are a male you 
already achieved; these women, "they can never do anything for themselves"; "she is just useless you know"). Further, the power struggle at play is illustrated by Ayanda: "look at those women coming to take our places now". Participant's internalisation of this discourse seems to have resulted in negative freedom (Foucault, 1980). Participants exercise reactive agency, rather than proactive agency, which may place restrictions for women more generally. For example, for those women who are still learning the technical field, it may limit their freedom to achieve self actualisation in their roles, or they may feel defeated; whereas positive and proactive agency provides women in general with freedom and a more empowered stance in dealing with these challenges/hegemonic discourse. These narratives suggest a dichotomous view of power which misses the fluid and dynamic intersections of power is complex social relations, where some men might for instance hold or be open to holding an alternative view of women. So in summary these participants seem to have painted themselves into a corner from which they shadow-box their invisible monster. However, in other parts of participants narratives, participants reveal transformative and pro-active thought processes, as a mechanism/tactic (Foucault, 1980) in viewing themselves in more egalitarian ways, in ways that do not distance themselves from men, and in ways that do not stereotype men as an opposing force..

The internal struggle that Foucault speaks to in terms of disciplinary power and surveillance. At this point in participant's narratives, there is a reflection of this 'invisible' force within the workplace, and many participants locate this force within themselves. Such reflections, as Egan (2006) highlights contain "a powerful transformative element [of therapy] that enables clients to reinterpret, or re-author, the events of their lives with new and different meanings and realities" (p. 31). 
In asserting their own agency position within the workplace, all participants perceived work challenges with a sense of an internal locus of control. By examining their own motivations, weaknesses, strengths and values, rather than structural elements in the workplace, allowed women to navigate themselves away from the position of victimhood to creators of their own lived experience.

In reflecting upon the challenges faced in the workplace, Nosipho locates these challenges within herself, and thus maintained a sense of control over her own path of development.

Nosipho: there were some challenges but I think most of them were within me...

Similarly, Sindi focuses on her own weaknesses by addressing them, rather than striving to compare herself to others:

Sindi: how I look at life, I always look within first and then the outside. I believe it will sort itself out so at that point.... you need to understand how you are, what are your weaknesses so that you can start addressing them, not suddenly comparing yourself to other people because they will never be like you, you are unique and then you need to understand that, you mustn't try and be other people...

Mbali reflects upon a common perception that women cannot do men's work. She takes agency in resisting and challenging this perception by arguing that many of these perceptions are biased towards women, and more accurately positions her work as something that is challenging 
to anyone [men included] without experience. She uses a specific example of the challenge she faced in learning to 'file' as an intern:

Mbali: So for us it was a challenge, not because it was a challenge to me as a woman, it was a challenge even to other guys...like I said with filing, when I was an apprentice I couldn't file but I just told myself if they can do it then I can also do it... because I can see that even some of our guys especially the South Africans they were battling, but the guys from Swaziland had more experience so they gave us the tips for how to do it ... and we all learnt...

\subsubsection{We as women ...}

All participants from this study, for their own reasons, emphasised that "as women, we need to support each other". Most participants linked this supportive role to their identity as a 'nurturer'. In addition to their drive to empower and develop all of their subordinates, participants specifically feel compelled to support and develop other women to create acceptance and a space for 'future generations of women'. Nolwandle states 'it is our obligation, as women, to support other women so that it gets better for future generations after us'. Nosipho feels compelled to transform the representation of women in leadership positions:

Nosipho: I have gotten to a point where I don't want to be successful for myself because it is boring, it is lonely at the top, I have no other one to talk to. So I would rather advise my friend this is how you should do it or another lady how don't you do it... 
Two heartening examples of the type of support participants are providing to other women in the workplace are recounted in the excerpts below. Participants are united as 'women' in their struggle against the system, thereby diminishing the existing racial and social divides that are so inherent in South African society.

The first excerpt is narrated by Rene, in terms of her experience in empowering one of her African female subordinates struggling to overcome both internal and external barriers to her development:

Rene: I just signed her on a few months ago so it's my mission to make her grow... she doesn't have that confidence yet, I mean she's just qualified, she doesn't have much experience yet...So I talk a lot to her... I say if the men come and mess you around you chase them away.... she's now actually starting to do that... You see, she has the same qualification as them, her certificate states that she is able to do these things... even the men are saying she has gotten better and more confident.

Mbali describes her experience where one Afrikaans woman was being discriminated against because of her gender, appearance and weight. Mbali and her female colleague fight for her, Mbali coaches her on how to conduct herself in an interview, however Mbali relates how men encourage women to get ahead - by 'putting on make-up' for the interview:

Mbali: There is this Afrikaans lady who been at Company Xfor over 10 years... She is fat like me, but she is very big. Sometimes she has this problem of being too emotional. 
Because of her weight, she has had mood swings. But she is a very good worker. Then last year we had vacancies, we interviewed her, but she cried in the interview. So I asked to see her again, I coached her... But the guys didn't want her... myself and a female colleague, we stood up for her..., One said I don't need her in my team. I said I will take her. If you guys don't want her I will take her. I will work with her, she is a very good worker. That guy said no, but we must tell her to put make up on that day, and I am like, what for? I was so disappointed in my colleagues, to just give me that comment that I must go and tell her to put her make up you know, but up until now I am still grooming her in terms of getting her self-esteem back. It is not easy, sometimes she fights with me, but I always say she is my baby...

The narratives presented reflect a common theme amongst women in terms of their collective identity. Women achieve solidarity in their shared definitions of themselves, "as women we care". All participants refer to themselves as part of the greater community of women in society ('we as women', signified by their common perception of issues that women face in mining (e.g. less opportunities for women, stereotypical images of women, oppressive forces that undermine women's confidence) and the similarities in their experiences in the workplace (women support each other). These experiences are internalised, forming what can be described as 'collective identity' - in this case, participants collective identity is established in their [collectively valued] moral obligation to support other women in mining; participants express an emotional connection with being 'caring' as a group; and finally their practices of supporting one another reinforces this 'collective identity'. Other characteristics discussed earlier in this chapter also relate to their collective identity as women, for example, they perceive themselves to be 
more sensitive (although they aim to become less sensitive in the workplace), they see themselves as nurturers, as more organised, etc. As such, participants narrate their identification with the broader category of 'women' as 'we as women', which can be conceptualised in terms of Melucci's (1989) conception of collective identity. Notwithstanding the risk of creating a reactionary in-group and reifying notions of caring, as a collective, women achieve agency in the social practice of supporting one another. By supporting each other, they enable other women to progress within the corporate ranks and as such achieve greater representation within the upper echelons of the business. Additionally, this collective identity enables women to achieve agency by cooperating with each other, and greater power as a group rather than as individuals. Thus, this identity can be considered as a 'mobilising identity' that may serve to sustain women's agency within Company X (Polletta \& Jasper (2001).

\section{$\underline{4.4 \text { Conclusion }}$}

The nature of identity that emerged from participant's narratives of the self can be viewed as an act of weaving together the multiple strands of the self, recognising the points at which these multiple strands intercept and where they diverge. So rather than merging these strands into a unified (and essentialist) self, participants seemed to recognise the fluid, dynamic and contextual sense of self and in-so-doing, participants began to, in their narrative, construct an authentic sense of self. The multiple strands of the self were presented as manifestations of reflexive interactions within social contexts. For the purpose of this study, the focus is on the shifts in subjectivities taking place when their 'work-self' intercepts alternative selves. At each interception participants are faced with (i) contradictions and ambiguity, causing what may be 
considered as 'identity conflict' or 'role conflict' (James 2009); or (ii) congruency of the self between roles, which emerged as 'identity salience' (Stryker and Burke 2000). From a poststructuralist perspective, the role of the researcher interprets the intercepts whereby the 'authentic' self interacts with alternative strains of the self (or socially sanctioned role prescriptions), as an illustration of the micro-physics of power, as postulated by Foucault (1979). Participant's engagement with role expectations within the workplace can be seen as either an internalisation of cultural prescriptions, whereby citizens restrict their life choices to fit socially sanctioned options or as a productive counter reaction where participants resist being defined in ways that are incongruent with their subject positions (Hooks, 1989). The latter reaction is what Foucault refers to as "discursive resistance" which "allows those who are 'subjects' of power to act otherwise and reject their confinement and self-subjugation within pre-determined discourses of power/knowledge" (Caldwell, 2007, p. 78). The resistance of socially prescribed roles can, in some cases, be seen as a form of agency (Caldwell, 2007). Further, such agency challenges dominant ideology, thereby driving shifts in the power dynamics of society (Ibid, 2007). 


\section{CHAPTER 5}

\section{CONCLUSIONS, RECOMMENDATIONS \& LIMITATIONS}

This chapter offers a summary of the main findings of the study and provides recommendations for intervention, policy and further research and discusses the limitations of the investigation.

\subsection{Summary of the main findings}

The aim of this research was to provide an account of the lived experience of women in senior positions in a mining organisation. Drawing from Social Constructionist and PostStructuralist paradigms, this study investigated three broad research questions: firstly, how women in mining narrate their experience; secondly, how women negotiate the tensions of a workplace that is both liberating and limiting; finally, what the implications of these tensions were for women's wellbeing and personal, community and cultural identities. As this study draws upon different, yet often overlapping theoretical positions, a thematic analytical approach was selected as the most appropriate method in analysing this data in that it offers an accessible and theoretically flexible approach to analysing qualitative data.

The three central and overlapping constructs, embedded in Social Constructionist and Post Structuralist epistemology, were examined throughout this research, viz., Identity, Power and Agency. Social Identity theory was utilised in examining the emergence of participant's multiple identity affiliations; a Foucauldian conceptualisation of power was adopted in order to examine the micro-physics of power and its productive functioning within the context of the 
organisation selected for this study; and the conceptualisation and analysis of agency was informed by the Social Constructionist and Post-Structuralist ontological position.

From a holistic perspective, participants' narratives were interpreted as an active involvement in constructing and weaving together multiple identities in the quest to achieve an authentic sense of self. In this endeavour, tensions emerged at cites of intercepting roles and identities, tied to various contexts.

A clear finding among all the participants is that women inhabit multiple identities. Women demonstrate multiple roles, values, beliefs, and affiliations. Participants defined themselves as mothers, wives, African women and leaders. Women with children were less invested in their careers in comparison with the single participants. However, all participants made reference to salient elements of their occupational identity that emerged within other roles that they occupy. This study indicated that each element of identity cannot be viewed in isolation.

In locating an authentic sense of self, these participants are caught between two incongruent positions, firstly, they seem to be battling against a perception that they are not 'man' enough to carry out their roles in the workplace, yet are considered not 'feminine' enough in relation to societal norms. This struggle is evident in women's incongruent conceptions of themselves within different contexts. On the one hand, these women perceive the need to be 'tough' and 'technically and physically competent', 'unemotional' and on the other hand, women 
position themselves as nurturers, mothers and carers. The gravitational pull between the ideal masculine' norm and the 'ideal feminine' norm, leaves women straddling in-between roles.

The subsequent discussion summaries the main findings in the context of each of the themes and subthemes:

Navigating the interceptions between occupational identity and multiple identities

\section{i. Navigating the intercepts of Personal and Occupational Identity}

At the interception of personal and occupational identities, participants juxtapose themselves in terms of traditionally 'masculine' and 'feminine' identities. On the one hand, participants' (to varied extents) conceptualise themselves as inherently 'soft'; on the other hand, and particularly in the context of the workplace, participants reject the confinement of being considered 'soft' and construct themselves in line with a more authoritarian notion of the self. Participants perceive this authoritarian notion of self as a masculine trait that enhances success at work; by contrast participants perceive 'softness' as a feminine trait that hinders success at work. From a Foucauldian (1980) perspective, participant's direct their gaze inwards and examine themselves in relation to what they perceive as 'effective' behaviour/traits within the context of work and discipline themselves to internalise what they perceive to be 'normative' behaviour/traits within a this context. Hence, participant's narratives in this regard suggest that women discipline themselves to embody 'masculinity'.

Participants' identities were not perceived as stable, they identify multiple selves, depending on the contexts in which they inhabit. They also recognise contexts in their lives 
which have shaped their identities. In constructing themselves as different from the 'other' women achieve a degree of agency in challenging the notion that women are physically too weak, not technically minded, or not interested in 'dirty, mine work'. However, when this comparison of the self is made in normative and polarised terms, participants reify stereotypes about women in general, exemplifying the 'while other women are like that, I'm not like other women' notion of identity.

\section{ii. Intercepting 'motherhood' in the workplace}

When the 'motherly' strain of the self intercepts the 'occupational' strain of the self, participants seemed to experience conflict in the extent to which they unveil their 'motherly nurturing' qualities. In contrast to empirical research which shows that women are generally more egalitarian and nurturing in their leadership style than men (e.g. Fine, 2007; Daft, 2005; Tamerius, 2005), the extent to which participants embody egalitarian leadership styles were strained by hegemonic norms. This creates conflict for women and 'negative freedom' (LewisWilliams, 2001) in exercising agency in embracing an authentic leadership style. It seems that a tension exists between bringing positive nurturing qualities to the workplace authentically against using traditional 'feminine' qualities such as nurturance and motherly discipline in disingenuous ways. Thus, what may be perceived by participant's as egalitarian, nurturing and transformational leadership qualities is actually a form of subtle authoritarianism which flies in the face of transformational leadership. 


\section{iii. The construction of a gendered work identity}

In their journey towards constructing and locating an authentic sense of self, participants' reject certain polarised and 'hegemonic masculine' traits in favour of more positive 'traditionally feminine' traits in the workplace context. This seems to create ambivalence within their own narratives that leaves them straddling two contradictory identities. At this point of interception (femininity and masculinity at work) participants begin to distance themselves from their notions of 'masculinity' in order to emphasise gendered differences, and in particular, aspects of 'femininity' that they embrace. In essence, women position and construct themselves as the 'other' by reifying hegemonic masculinity. Participant's narratives therefore vindicate Talbot and Quayle's (2010) argument that, not only men but women too, are active agents in the production and maintenance of masculinities and emphasised femininity.

\section{iv. The deconstruction of ethnic identity in the workplace}

At the interception of ethnic and occupational identities, participants question the efficacy of their ethnic identities, resulting in an ambiguous account of who 'we' are and who 'they' are, leading women to question the salience of their ethnic identities as a mobilising identity. Results also reveal greater pressure to conform to in-group pressures. Nevertheless, some participants achieve a sense of agency in constructing themselves in prosocial (Joireman, 1994) ways.

\section{v. Keeping all my diamonds intact}

In keeping with the literature, participants viewed their work as central to their lives, a means to attain self-fulfilment and the fulfilment of their economic needs (Haworth \& Lewis, 2005; Koekemoer \& Mostert, 2010). Participants narratives illustrate several juxtapositions in 
their choices, (e.g. being seen as an uncaring mother, or not progressing at work; being unable to provide for their children or being seen as an 'absent' mother; facing the stigma of being a 'bad mother' or 'bad wife'). This is the terrain in challenging hegemonic or dominant ideological positions, e.g. Hook (2002). However, there was a silence in participant's narratives regarding challenging the role of their husbands/partners to develop more egalitarian relationships. Participants take on the role of 'carer' in an uncontested way in their narratives. An intervention that reinforces prosocial values and behaviours (Joiermen, 1994) and that includes men, is recommended to deconstruct hegemonic ideology and subsequently free both men and women from their own hegemony (Lund 2006; Morrell \& Jewkes, 2011; Madhavan et al, 2008).

\section{Negotiating a space for women in mining}

\section{i. Challenging the 'invisible monster'}

Participants conceptualise hegemonic practices within the organisation as something that exists as an invisible force, creating a perception of an 'invisible' monster. Participants narratives illustrate a need to challenge existing gendered discourse that seems to subordinate women while reinforcing men's dominant position within the ranks of the organisation. Subsequent internalisation of this discourse, seems to have resulted in participants exercising negative freedom, in 'proving' they can make it in a 'man's world'. Participants challenge these gendered norms by constantly evaluating and working at proving their competencies. This type of agency can be interpreted as a form of reactive, rather than proactive agency. For example, for those women who are still learning the technical field, it may limit their freedom to achieve selfactualisation in their roles which may be self-defeating. Whereas positive, proactive agency provides women with freedom and a more empowered stance in dealing with these 
challenges/hegemonic discourses. In this regard, participant's narratives suggest a dichotomous view of power which misses the fluid and dynamic intersections of power within complex social relations, where some men might for instance hold or be open to holding an alternative view of women. In effect, participants painted themselves into a corner from which they shadow-box their invisible monster. In asserting their own agency position within the workplace, all participants perceived work challenges with a sense of an internal locus of control. By examining their own motivations, weaknesses, strengths and values, rather than structural elements in the workplace, allowed women to navigate themselves away from the position of victimhood to creators of their own lived experience.

\section{ii. We as women ...}

All participants from this study, for their own reasons, emphasised that "as women, we need to support each other". In addition to their drive to empower and develop all of their subordinates, participants specifically feel compelled to support and develop other women to create acceptance and a space for 'future generations of women'. The narratives presented reflect a common theme amongst women in terms of their collective identity. Women achieve solidarity in their shared definitions of themselves, "as women we care". By supporting each other, they enable other women to progress within the corporate ranks and as such achieve greater representation within the upper echelons of the organisation. Additionally, this collective identity enables women to achieve agency by cooperating with each other, and greater power as a group rather than as individuals. Thus, this identity can be considered as a 'mobilising identity' that may serve to sustain women's agency within Company X (Polletta \& Jasper, 2001). 


\section{$\underline{5.2 \text { Intervention and recommendations }}$}

Many scholars argue that by incorporating Ubuntu as a leadership philosophy into present organisational structures in South Africa, there is the potential to create more egalitarian, transparent and democratic social relations (Ncube, 2010; Mbigi, 1997; van Binsbergen, 2001). As a postcolonial paradigm, Ubuntu offers an inclusive discourse on leadership that incorporates marginalised traditions (Ncube, 2010). In addition, the new leadership paradigm, such as the transformational leadership paradigm (French 1991; Bryman, 1996; Ayaman and Korabrik, 2010) may serve as a counter-discourse for women to embrace in resisting the normative autocratic prescriptions of an 'effective leader'. The transformational leadership approach encourages leaders to utilise a more androgynous leadership style, which may authenticate women's own preferences in engaging with their teams (Ayaman \& Korabik, 2010). Further, such an approach may increase 'leadership effectiveness' across the organisation (French 1991; Bryman, 1996). Ayaman and Korabik (2010) suggest that examining more androgenous notions of leadership may facilitate the process of eradicating the masculine stereotypical image of a leader, eliminating the ethnocentrism that creates ingroup - outgroup biases, and equalizing access to power and privilege.

It is important to note that in future training initiatives, women may achieve greater agency if they were to adopt the prosocial orientation (Joireman, 1994), where they reflect upon their own narratives and question the accuracy thereof. Creating a space for women to question these normative prescriptions of gender may serve to 'free' women who may be confined to such roles (Lewis-Williams, 2001). In light of Foucault's argument regarding the micro-physics of power, women who are actively involved in questioning the validity of stereotypical notions of 
the feminine self take agency in deconstructing such notions, thus limiting the extent to which such images are perpetuated in society (Hook, 2004).

Another recommendation is for Company $\mathrm{X}$ to provide coaching for women to find their own voices and unique ways of negotiating their identity and space in the work-force. The research findings would assist human resource practitioners to develop training interventions and management strategies to potentially enhance work-based identities. More clearly developed work-based identities could therefore assist in the development of a more harmonised South African workplace. Creating a space for women to question these normative prescriptions of gender may serve to 'free' women who may be confined to such roles (Lewis-Williams, 2001).

In addition to providing a platform for women to exercise agency in their own identity constructions, it is pivotal that men are concluded. Lund (2006) Morrell \& Jewkes, (2011) and Madhavan et al, (2008), suggest an intervention that reinforces prosocial values and behaviours, to deconstruct hegemonic ideology and subsequently free both men and women from their own hegemony.

\section{$\underline{5.3 \text { Limitations and recommendations for future research }}$}

One of the limitations of this study is that it excluded the analysis of the historical development of public discourse related to gender in South Africa. The investigation of language change in public discourse is a powerful method of examining ideological developments in society (Phleps \& Nadim, 2010). A study which incorporates both macro and micro physics of 
power creates a holistic view in terms of linking the ideological changes within the micro-sphere with changes in the macro-sphere, as discussed by Hook (2004). This analysis was beyond the scope of this study however; despite this limitation this study has value in representing the bottom-up conduits of power on which hegemonic forms of power exist (McHoul \& Grace, 1993).

Due to the limited sample size, and the use of a convenience sample, this study makes no claim for generalizability. However, the way in which participants narrate their experience in terms of both their practices and gendered understandings has implications for gender equality. Therefore, the findings of this study are restricted in application to the participants studied. Future research that confirms or disconfirms the findings from this study is required in order to develop a more comprehensive understanding of women in the mining sector, particularly due to the lack of research in this area. Due to time restraints, follow-up interviews were not carried out. Reliability of the researcher's interpretation may have been increased had participants been involved in verifying the data analysis for accuracy. It is recommended that future studies incorporate men and women, to obtain a fuller understanding of gender an power dynamics in creating and sustaining normative prescriptions of 'masculinity' and 'femininity' in the mining sector. Further, a cross-sectional analysis of both senior and front-line employees is required in order to inform more inclusive interventions.

One of the findings from participant's narratives was the enhanced pressures of in-group conformity in relation to ethnic groups. Due to limitations in scope of this research, this finding 
was not explored in greater depth. There is therefore a need for future research which explores gendered intra-group and intra-racial conflict in the South African mining sector. 


\section{REFERENCES}

Abrams, D., \& Hogg, M. A. (1990). Social identity theory: Constructive and critical advances. New York, NY US: Springer-Verlag Publishing.

Alan, J. \& Turner, L. (1986). Frantz Fanon, Soweto and American blacks. Chicago: News \& Letters Publication.

Allen, T.D., Herst, D.E.L., Bruck, C.S., \& Sutton, M. (2000). Consequences associated with work-to-family conflict: A review and agenda for future research. Journal of Occupational Health Psychology, 5(2), 278-308.

Anderson, H., \& Goolishian, H. (1988). Human systems as linguistic systems: Evolving ideas about the implications for theory and practice. Family Process, 27, 371-393.

Anderson, R. E. (2004). Gender and computers: Understanding the digital divide. Journal of Marriage and Family, 66 (2) 542-543.

April, Dreyer and Blaas (2007). Gender impediments to the South African Executive Boardroom. South African Journal of Labour Relations, 31(2), 51-67.

Ayman, R., \& Korabik, K. (2010). Leadership: Why gender and culture matter. American Psychologist, 65(3), 157-170.

Banjeree, A. (2007). Foucault's analysis of mental illness: A Psycho-pathological study. New Delhi: Book Publisher

Bolowana, A. (2005, February 15). Men still rule in workplace. Pretoria News. 
Booysen, L. (2007). Social identity challenges: challenges facing leadership, in Diversity in Africa: the coming of age of a continent, edited by K. April \& M. Shockley. Basingstoke: Palgrave Macmillan.

Botha, C., Fourie, J.D., Botha, D. and C. Bischof. (2012). Progress in implementing the Mineral and Petroleum Resources Development Act 28 of 2002 (MPRDA) provisions for the employment of women in mining. The Journal of The Southern African Institute of Mining and Metallurgy, 112, 395-404.

Bradley, H. and Healy, G. (2008). Ethnicity and Gender at Work. Basingstoke, Palgrave Macmillan.

Braun, V. and Clarke, V. (2006). Using thematic analysis in psychology. Qualitative Research in Psychology, 3, 77-101.

Brehm, S. S., Kassin. S. M., and Fein, M. (2005). Social Psychology. Boston: Houghton Mifflin Company.

Broad-based Socio Economic Empowerment Charter for the South African Mining Industry. http://www.dme.gov.za/.

Broadbridge, A. (2008). Senior careers in retailing: An exploration of male and female executives' career facilitators and barriers. Gender in Management. An International Journal, 23(1), 11-35.

Bryman, A. (1996). Leadership in Organisations. In S.R. Clegg, C. Hardy \& W.R. Nord (Eds), Handbook of Organization Studies (pp 276-292). London: SAGE Publications. 
Burr, V. (1995). An introduction to social constructionism. Florence, KY US: Taylor \& Frances/Routledge.

Butler, J. (1994). Contingent foundations: feminism and the question of post-modernism. In S. Seidman (Ed.), The postmodern turn: new perspectives on social theory (pp. 153-170). Cambridge: Cambridge University Press.

Caldwell, R. (2007). Agency and change: Re-evaluating Foucault's legacy. Organization, 14(6), 769-789.

Daft, R. L. (2005). The leadership experience. Toronto: Webcom Limited.

Davies, L. (2000). The civil school and civil society: Gender, democracy and development. In M. Arnot \& J. Dillabough (Eds.), Challenging Democracy: International Perspectives on Gender, Education and Citizenship. (pp. 278 - 296). London: Routledge.

Durrheim, K. (1997). Social constructionism discourse and psychology. South African Journal of Psychology, 27 (3), 175-182.

Duveen, G. (2001). Representations, Identities and Resistance. In K. Deux \& G. Philogène (Eds.) Representations of the Social. Oxford: Blackwell.

Eagly, A. H., \& Carli, L. (2007). Through the labyrinth: The truth about how women become leaders. Boston, MA: Harvard Business School Press.

Eagly, A.H. and Karau, S.J. (2002). Role congruity theory of prejudice towards female leaders. Psychological Review, 109, 573-598. 
Eby, L.T., Casper, W.J., Lockwood, C.B., Bordeaux, C., \& Brinley, A. (2005). Work and family research in IO/OB: Content analysis and review of the literature (1980-2002). Journal of Vocational Behavior, 66, 124-197.

Egan, G. (2006). The skilled helper: A problem management and opportunity development approach to helping. California: Brookes Cole.

Ely, R. J. (1995). The power in demography: women's social constructions of gender identity at work. Academy of Management Journal, 38(3), 589-634.

Epston, D., White, M., \& Murray, K. (1992). A proposal for a re-authoring therapy: Rose's revisioning of her life and a commentary. In S. McNamee, K. J. Gergen (Eds.), Therapy as social construction (pp. 96-115). Thousand Oaks, CA US: Sage Publications, Inc.

Ferree, M. M. (1995). Beyond separate spheres: Feminism and family research. In G. Bowen \& J. Pittman (Eds.), The work and family interface: Toward a contextual effects perspective (pp. 122-137). Minneapolis, MN: National Council on Family Relations.

Festinger, L. (1954). A theory of social comparison processes. Human Relations, 7, 117-140.

Finchilescu, G. (2005). Meta-stereotypes may hinder inter-racial contact. South African Journal of Psychology, 35(3), 460-472.

Fine, M. G. (2007). Women, collaboration, and social change: An ethics-based model of leadership. In J. L. Chin., B. Lott., J. K. Rice \& J. Sanchez-Hucles (Eds.), Women and leadership: transforming visions and diverse voices. MA. USA. Blackwell Publishing (p.177-109). 
Foucault, M. (1977). Discipline and punish: The birth of the prison. Middlesex: Peregrine.

Foucault, M. (1980). Power/Knowledge: Selected Interviews and Other Writings by Michel Foucault. New York: Pantheon Books.

Foucault, M. (1984). Nietzsche, Genealogy, History, In P. Rabinow (ed.), The Foucault Reader, (pp. 76-100). New York: Pantheon

Frone, M.R. (2003). Work-family balance. In J.C. Quick \& L.E. Tetrick (Eds.), The Handbook of Occupational Health Psychology, (pp. 143-162). Washington: American Psychological Association.

Gergen, K. J. (1999). Invitation to social constructionism. London: Sage.

Gillespie, R. (2003). Childfree and feminine: Understanding the gender identity of voluntarily childless women. Gender \& Society, 17(1), 122-136.

Gounden, V. (2010). Reflections on Identity Conflicts and Nation Building in Contemporary South Africa. South Asian Journal of Peacebuilding, 3(2), 1-5.

Grimshaw, J. (1986). Philosophy and Feminist Thinking. Minneapolis: University of Minnesota Press.

Grobler, P.A. (1996) In search of excellence: leadership challenges facing companies in the new South Africa. Sam Advanced Management Journal, 22-41.

Gubrium, J.F. and Sankar, A. (1994). Qualitative methods in aging research. Thousand Oaks: Sage Publications Ltd. 
Haworth, J.T., Lewis, S.N. (2005). Work, leisure and well-Being. British Journal of Guidance and Counselling, 33(1) 67-7.

Hogg, M. A. \& Abrams, D. (1990) Social Identity Theory: Constructive and Critical Advances. London: Harvester Wheatsheaf.

Holland, D., Lachicotte Jr. W., Skinner, D. and Cain, C. (2001). Identity and Agency in Cultural Worlds. Cambridge, Mass.: Harvard University Pres.

Holloway, I. and Todres, L. (2003). The status of method: flexibility, consistency and coherence. Qualitative Research, 3, 345-57.

Holoway, M., Byrne, D. \& Titlestad, M. (2001). Love, power and meaning. South Africa: Oxford University Press.

Hook, D. (2004). Foucault, Disciplinary Power and the Critical Pre-History of Psychology. In D. Hook, Critical Psychology (pp. 210-238). Cape Town: UCT Press.

Hoy, D. C. (1986). Power, Repression, Progress: Foucault, Lukes, and the Frankfurt School. In D. Hoy (Ed.), Foucault: A Critical Reader, (pp. 123-147). London: Blackwell.

Inden, R. (1990). Imagining India. Oxford: Blackwell

James, W. (2009). Perspectives of Executive Women: Life Choices and Balancing Career with Marriage and Children. Unpublished doctoral dissertation, Waldon University, Minneapolis. 
Jordan, G., \& Weedon, C. (1995). Cultural politics: class, race, gender and the post-modern world. Oxford: Blackwell Publishers.

Kellerman, B., \& Rhode, L. D. (2007). Women and leadership: The state of play and strategies for change. California: Jossey-Bass.

Koekemoer, E., \& Mostert, K. (2010). An exploratory study of the interaction between work and personal life: Experiences of South African employees. SA Journal of Industrial Psychology, 36(1), Art. \#801, 15 pages. DOI: 10.4102/sajip.v36i1.801

Kruger, L. M. (2006). Motherhood, in T. Shefer, T. F. Boozaier,, \& P. Kiguwa (eds), The gender of psychology. Cape Town: UCT Press.

Lahiri-Dutt, K. \& Macintyre, M. (2006). Women Miners in Developing Countries: Pit Women and Others. Ashgate: Aldershot.

Lax, W. (1994). Postmodern thinking in a clinical practice. In S. McNamee \& K. Gergen (Eds.), Therapy as social construction (pp. 69-85). Newbury Park, CA: Sage.

Lewis-Enright, K., Crafford, A., and Crous, F. (2009). Towards a workplace conducive to the career advancement of women. South African Journal of Industrial Psychology, 35 (1), 136-144.

Lewis-Williams, K. (2001). Identity, culture and power: Towards frameworks for selfdetermination of communities at the margins. Unpublished doctoral dissertation, Massey University Albany, New-Zealand. 
Lloyd, S., Roodt, G., \& Odendaal, A. (2011). Critical elements in defining work-based identity in a post-apartheid South Africa. South African Journal of Industrial Psychology, 37(1), $53-67$

Lund, F. (2006). Gender and Social Security in South Africa, in V. Padayachee (ed.) The Development Decade? Economic and Social Change in South Africa 1994-2004, pp. 160- 79. Cape Town: Human Sciences Research Council.

Madhavan, S., Townsend, N.W., Garey, A. (2008). 'Absent breadwinners': Father-child connections and paternal support in rural South Africa. Journal of Southern African Studies, 34(3), 647-663.

Mama, A. (1995). Beyond the masks: Race, gender and subjectivity. London: Routledge.

Mamabolo, I., Langa, M., \& Kiguwa, P. (2009). To be or not to be a mother: exploring the notion of motherhood among university students. South African Journal of Psychology, $39(4), 480-488$.

Maroda, K. J. (2004). A relational perspective on women and power. Psychoanalytic

Mather-Helm, B. (2005). Equal opportunity and affirmative action for South African women: a benefit or barrier? Women in Management Review, 20(1), 56-71.

Mbigi, L. (1997). Ubuntu: The African dream in management. Randburg, South Africa: Knowledge Resources. 
McHoul, A., \& Grace, W. (1993). A Foucault Primer: Discourse, Power and the Subject. London: UCL Press.

Melucci, A. (1989). Nomads of the Present: Social Movements and Individual Needs in Contemporary Society Philadelphia: Temple University Press

MMSD (2001). Mining Minerals Sustainable Development South Africa. International Institute for Environmental and Development (IIED).

Morrell, R., \& Jewkes, R. (2011). Carework and caring: A path to gender equitable practices among men in South Africa?. International Journal for Equity In Health, 10(1), 17-26.

Mostert, K. (2009). The balance between work and home: The relationship between work and home demands and ill health of employed females. SA Journal of Industrial Psychology, 35(1), Art. \#743, 8 pages. DOI: 10.4102/ sajip.v35i1.743

Mphokane, M.S. (2008). Profiles of 'Successful Managers' in the coal mining industry. Unpublished Masters of Business Administration Dissertation, University of Pretoria.

Naidoo, A. A., \& Jano, R. R. (2002). Role salience of dual-career women managers. South African Journal of Industrial Psychology, 28(3), 69-74.

Ncube, L. B. (2010). Ubuntu: A transformative leadership philosophy. Journal Of Leadership Studies, 4(3), 77-82.

O’Brien, M., \& Penna, S. (1998). Theorising welfare: enlightenment and modern society. London: Sage Publications. 
Parker, I (1999). Critical textwork: an introduction to varieties of discourse and analysis. Buckingham : Open University Press.

Polletta, F. and Jasper, J. (2001). Collective Identity and Social Movements. Annual Review of Sociology, 27, 283-305.

Pranit, K. (2010). Organisational Behaviour. Delhi: Young Art Press

Rappaport, A. (1990). The staying power of the public corporation. Harvard Business Review, 1, 96-104.

Republic of South Africa. (1995). Labour Relations Act, No. 66 of 1995. Pretoria: Government Printers.

Republic of South Africa. (1998). The Employment Equity Act, No. 55 of 1998. Pretoria: Government Printers.

Republic of South Africa. (2000). The Preferential Procurement Framework Act, No. 5 of 2000. Pretoria: Government Printers.

Republic of South Africa. (2002). The Mineral and Petroleum Resources Development Act, No. 28 of 2002. Pretoria: Government Printers.

Republic of South Africa. (2003). The Broad-Based Black Economic Empowerment Act, No. 53 of 2003. Pretoria: Government Printers. 
Ristow, A.M., Amos, T.L., \& Staude, G.E. (1999). Transformational Leadership and organisational effectiveness in administration of cricket in South Africa. South African journal of Business Management, 30(1) 1-5.

Rosenau, P. (1994). Health politics meets postmodernism: its meanings and implications for community health organizing. Journal of Health, Politics, Policy and Law, 19(2), 303333.

Rowe, T.T., \& Crafford, A.A. (2003). A study of barriers to career advancement for professional women in investment banking. SA Journal of Human Resource Management, 1(2), 21-27

Saayman, T., \& Crafford, A. (2011). Negotiating work identity. South African Journal of Industrial Psychology, 37(1), 207-218.

Smart, B. (1985). Michel Foucault. London: Routledge.

Stangor, C., \& Schaller, M. (2000). Stereotypes as individual and collective representations. In C. Stangor (Ed.), Stereotypes and prejudice: Essential readings (pp. 64-82). New York, NY US: Psychology Press

Stewart, A. (1998). The ethnographer's method. California: Sage Publications Ltd.

Strauss, A.L. \& Corbin, J.M. (1990). Basics of qualitative research: grounded theory procedures and techniques. Newbury Park, CA: Sage.

Swann, W., \& Bosson, J. (2009). Self and Identity. In S. T. Fiske et al (Eds.), Handbook of Social Psychology (pp. 580-592). New Jersey: John Wiley \& Sons. 
Tajfel, H., \& Turner, J.C. (1986). The social identity theory of intergroup behavior. In S.

Talbot, K., \& Quayle, M. (2010). The Perils of Being a Nice Guy: Contextual Variation in Five Young Women's Constructions of Acceptable Hegemonic and Alternative Masculinities. Men \& Masculinities, 13(2), 255-278.

Tamerius, K. L. (1995). Sex, gender, and leadership in the representation of women. In G.

Duerst-Lahti \& R. M. Kelly, (Eds.), Gender power, leadership, and governance. (pp. 93112).U.S.: The University of Michigan Press.

The Bill of Rights of the Constitution of the Republic of South African. (1996). Government Gazette. (No. 17678).

van Binsbergen (2001). Ubuntu and the globalization of Southern African thought and society. Quest: An African Journal of Philosophy, 15(1-2).

Van Manen, M. (1990). Researching lived experience. University of New York Press, New York.

Verkuyten, M. (2005). The social psychology of ethnic identity. New York: Psychology Press.

Volman, M. and Dam, G. T. (1998). Equal but different: contradictions in the development of gender identity in the 1990's. British Journal of Sociology of Education, 19(4), 529-545.

West, C. \& Zimmerman, D. (1987). Doing gender. Gender \& Society. (1), 1251-51.

White, M. (1991). Folk psychology and narrative practice. Dulwich Centre Journal (2). 
Whitely, B. E. (2002). Principles of research in behavioural science. New York: McGraw-Hill.

Wilkonson, C. W. (1989). A critical guide to the literature of women coal miners. Labour Studies Journal, 25-45.

Yuval-Davis, N. (1993). Beyond difference: Women and coalition politics. In M. Kennedy, C. Lubelska \& V. Walsh (Eds.), Making Connections: Women's Studies, Women's Movement, Women's Lives. (pp. 3 - 10). Abingdon, Oxon: Taylor \& Francis. 


\section{Appendix A: Interview Schedule}

\section{Background information}

To begin, could you tell me about yourself

Probes: age, work experience, ethnicity (religion), education, marital \& family background, how long have you been at Company $\mathrm{X}$

What is your role at Company $\mathrm{X}$ - what is a typical day like for you?

How did you get to where you are?

\section{Identity}

What roles do you carry out on a day to day basis

What does it mean to be a successful "woman" for you?

What traits are important for success (in your marriage, work, home, community?)

If your view of what it is to be a successful manager is different from the traditional male view, how does this impact on your relationship with men? Did this impact on your career? How?

Can you describe any differences between yourself and your male colleagues?

If your identity (who you are as a person) is in any way different to others at Company X, how does this impact on your relationship with them? How does this affect your work?

\section{Social Identity}

Sometimes women are not recognised properly by the dominant culture. And people who make decisions may not understand the issues that women face in the same way as the people who are affected by them more directly.

- What sorts of barriers do you/women in your team/women at Company X face?

- What barriers are faced when you/they tried to do something about it?

- Do you notice ways in which commonly held views about women or groups "black women/Indian women/white women" affect the way in which women see themselves?

- Does this affect the way in which they take action to solve problems?

- Does this affect the way you take action to solve problems/resolve issues?

- Can you tell me any examples or stories that you may recall 


\section{Agency}

Have there been instances where men or women at Company $\mathrm{X}$ have not been enabling of team members exercising new roles and increased personal power? How did you know this? What do you think allowed for this to happen? Is there a story you can tell me that highlights this?

If you had more/less authority or social status in the eyes of your team, how did your team know this? And was this significantly reflected in the work of your team?

Did you experience any tensions/difficulties in managing accountability within the work environment? If so, in what ways?

Was there any resistance in terms of you becoming a leader at Company $\mathrm{X}$ because you are a woman? How did you overcome this? Did you form any partnerships with other groups to help maintain your position?

What are the challenges of working in a multicultural environment (i.e. being black, being a woman, having high qualifications, being young...)?

What are the positive experiences you have had here at RBM in general and as a woman?

Are there any tensions that you experience navigating across different roles (point to contradictions)

How have you managed these tensions? 


\section{Appendix B: Ethical Clearance}

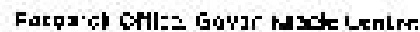

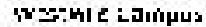

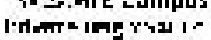

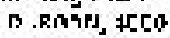

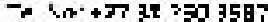
$\mathrm{F}: \mathrm{x}<6,+27$ 31 $43045 \mathrm{CD}$ ir

$\eta \operatorname{lir}=\mathbf{r}$

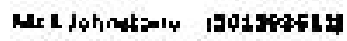

Fhan $\sigma^{\circ}$ Frdiolog/

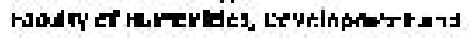

s:m is te:t

Hmund Ind 20 Crenpile

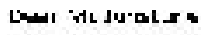

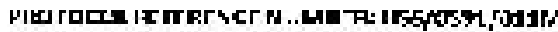

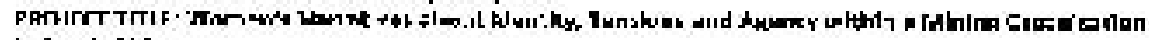

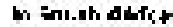

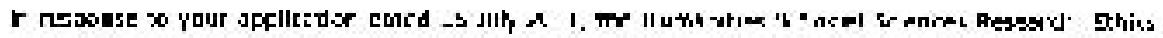

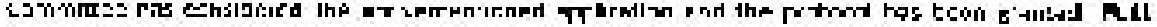
NTTEVYAL

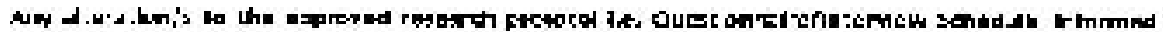

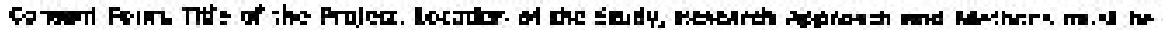

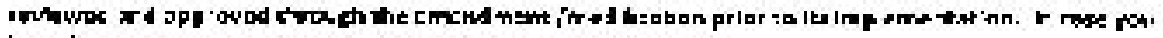

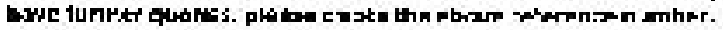

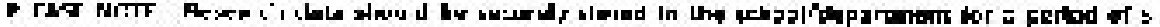
yods.

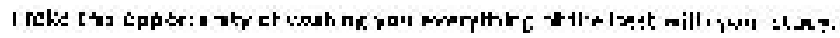

von'slaill hli

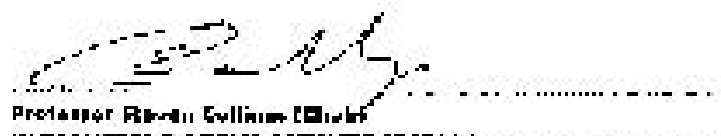

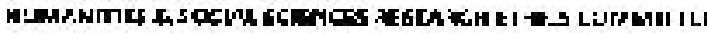

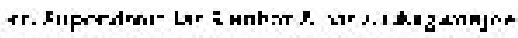

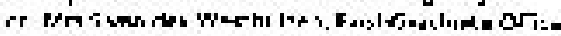

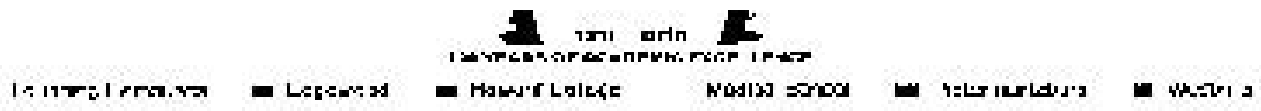




\section{Appendix C: Permission Letter From Company X}

\section{Company $\mathrm{X}$}

30 May 2011

The Chair

Higher Degrees Committee

Faculty of Humanities, Development and Social Sciences

University of KwaZulu-Natal

RE: Request to conduct research study, Leigh Johnstone, Title of study: Women's Narratives about Identity, Power and Agency within a Mining Organisation in South Africa

I have read Ms. Johnstone's draft research proposal and am pleased to support this study being conducted at Company $\mathrm{X}$, subject to Ethical Clearance being granted by UKZN.

I believe that the research addresses critical issues confronting RBM and the South African workplace more generally. We look forward to receiving Ms Johnstone's research report and assure you of our commitment to draw on the learnings produced in informing our organisational transformation initiatives.

Yours Sincerely

Managing Director

Company $\mathrm{X}$ 


\section{Appendix D: Informed Consent Form}

School of Psychology

$\underline{\text { Letter of Informed Consent }}$

Date:

$\mathrm{I}$, state that I agree to participate in a research project conducted by Leigh Johnstone who is a Masters Industrial Psychology student at the University of KwaZulu- Natal, Durban.

I understand that the research being conducted will provide insight into my experiences at work, at home and within the community. Such information will be used to improve the company's programs and policies. I agree to participate in an individual interview group discussion.

I acknowledge that Leigh Johnstone has explained the task to me fully; has informed me that I may withdraw from participation at any time without prejudice or penalty; has offered to answer any questions that I might have concerning the research procedure; has assured me that information obtained will be reported collectively, without identifying me personally thereby ensuring anonymity; the information will be confidential; and that the results of this study will be reported to the organization and may take the form of published outputs.

Signature of Researcher

Leigh Johnstone

Student number 201293612

Cell: 0718796386
Signature of Participant

Supervisors Signature

Anil Bhagwanjee

Tel: 0312014241

School of Psychology

UKZN

If you wish to obtain information on your rights as a participant, please contact Ms

Phumelele Ximba, Research Office, UKZN, on 0313603587. 